\title{
How Effective are Policy Interventions in a Spatially-embedded International Real Estate Market?
}

\begin{abstract}
We introduce the role of 'space' in analysing the effect of macroeconomic policy interventions on cross-country housing price movements. We build an empirically testable analytical model and test our theoretical predictions for a panel of European countries over the period 1985-2015. Our aim is to demonstrate that while macroeconomic policy exerts a significant impact on international housing markets, the magnitude of such impacts may be overestimated in the absence of spatial frictions. To test our hypotheses, we employ a spatial dynamic panel method and quantify intra- and inter-country differences of the effects of macroeconomic policy interventions on spatially interdependent housing markets. Endogeneity issues arise in our estimation, which we ameliorate by employing the spatial Durbin model for panel data. Following this approach, we include spatial, temporal and spatio-temporal lags for identification purposes. We show that a spatially-embedded model produces relatively smaller and correct signs for macroeconomic variables in contrast to the traditional non-spatial model. It is concluded that empirical estimates from the traditional model are consistently over-estimated. These have significant policy implications for the exact role of macroeconomic interventions in housing price movements. A battery of robustness tests and evaluations of predictive performance confirm our results.
\end{abstract}

Key Words: Housing price variations; Macroeconomic adjustments; Spatial frictions; Real estate market; Spatial dynamic panel regression; Estimation bias.

JEL Classifications: C33; E32; E60; E62; R03; R31 


\section{Introduction}

\subsection{Context and contribution}

A growing body of empirical evidence supports the hypothesis that macroeconomic policy interventions, at both national and international levels, significantly determine house price movements both within and across a country's geographic boundary. ${ }^{1}$ For instance, a rise in interest rates can dampen housing demand in a country as house purchases become costlier. In fact, such policy strategies are often employed in an economy to control inflationary impacts of excess demand. Similarly, the government may wish to boost housing demand by announcing tax reductions and interest rate cuts. On the other hand, housing supply can be enhanced by increasing credit flow to real-estate developers so that they are motivated to invest in new housing construction projects. To summarize, macroeconomic instruments ${ }^{2}$ can be considered as credible tools for controlling housing demand and supply. These results are interesting as the determination of housing prices can move beyond hedonic variables and can find a natural control mechanism in macroeconomic adjustments. Undoubtedly, while these observed findings have opened up a new direction of research in the real estate market context, consideration of spillover effects in an empirical model can lend better predictive power to the effects of macroeconomic variables. A failure to account for such effects may result in over-reaction of the macroeconomic system and policy-ineffectiveness in the housing market. ${ }^{3}$ The current paper contributes to this sparse literature and aims to fill a gap by introducing the role of 'space' in modeling real estate prices and the macroeconomic relationship.

Indeed, no economic actions are free from the dynamic effects of 'space'. The vast literature of economic geography shows that 'space' can act as a medium through which agents can learn and adapt. Therefore, the real effects of a shock in one location is felt in 'moderation' in an adjacent location. Such an observation means that the model under consideration is stationary in the spatio-temporal domain; that is, the spatial effects decline over time and 'distance'. ${ }^{4}$ Under the assumption of a 'spatial attribute', then any policy adjustment in a specific location, should have a large impact on the local economy, but a smaller impact in adjacent economies. In sum, given our current context of a housing price-macroeconomy interaction setting, any inference without spatial dynamics may lead to biased inferences about the true effect of the macroeconomic ad-

\footnotetext{
${ }^{1}$ Notable work in this regard include Hilbers et al. (2008), Beltratti and Morana (2010),Vansteenkiste and Hiebert (2011), Bagliano and Morana (2012), Cesa-Bianchi (2013) and Arestis and Gonzalez-Martinez (2016), among others.

${ }^{2}$ We use macroeconomic policy intervention, policy adjustments and instruments interchangeably throughout the paper. Two distinct sets of macroeconomic policy variables are used. First, variables such as interest rate and taxation on property are under direct control of monetary and fiscal authorities. Second, there are general macroeconomic variables, such as current account balance and unemployment rate, which are indirectly determined by policy interventions.

${ }^{3}$ If policy makers do not have adequate knowledge of the extent of the spillover effects, they may unknowingly overemphasize the role of macroeconomic interventions for disequilibrium corrections in the housing market and ultimately lead to the 'overheating of the economy'.

${ }^{4}$ If frictions in one location completely transfer to another location, they give rise to spatial non-stationarity. A non-stationary spatial model, similar to a non-stationary time series model, possesses undesirable properties of the estimators, and thus gives rise to very large standard errors.
} 
justment process in housing price movements. Interestingly, 'space' as a determinant seems to be missing from the existing theoretical construct for country-specific empirical studies of housing price dynamics.

Accordingly, we argue in this paper - using both analytical results and empirical insights - that although macroeconomic policy adjustment is important in controlling housing price fluctuations, its interactions with the spatial attribute are also equally important. ${ }^{5}$ We show empirically that disregarding 'space' from an estimation produces over-estimated effects of macroeconomic variables on housing prices. This estimation bias can lead to over-emphasis of the role of the macroeconomic adjustment process in dealing with housing price fluctuations and under-reaction of the housing market over time. We contribute to the literature in the following ways.

First, we consider an interdependent international house price model. The interdependence in our work is modelled by spatio-temporal spillover effects. We define 'space' by geographical locations, where it is supposed that within a common-market economic boundary (viz.,the European market), the locational effects can play an important role towards realizing the true effects of macroeconomic variables in housing price movements. Our approach is also different from common practice where regional-level hedonic pricing behavior is studied within a single country setting. Wherever a multi-country context has been employed, there is little we know of the explicit treatment of 'space' within the existing theoretical framework. In this sense, ours is among the very few studies which examine the moderating role of space in macroeconomy-housing market studies from an international perspective.

Second, we develop an empirically testable analytical framework that models spatial-spillover effects in the cross-country macroeconomy-housing market relationship. We study the properties of this model and empirically determine the extent of bias in the estimates of macroeconomic policy variations in the housing market. This bias is then quantified by estimating a dynamic spatial panel model for European countries over the last three decades. We estimate our model, where we clearly distinguish between direct and indirect effects of these variables, and then go on to test the predictive power of the model with a series of robustness checks. To the best of our knowledge, ours is the first such study to develop a spatial framework for modeling the crosscountry macroeconomy-housing market relationship.

\subsection{Why Europe?}

We choose a panel of European economies for our empirical investigation. The choice is motivated by a number of factors. First, European economies share a 'common market' and follow similar macroeconomic governance structures (see Campos et al. (2014)). From this perspective, all economies within Europe can be regarded as belonging to a common economic region. Moreover, these economies share geographic borders. On the whole, both economic and geographic

\footnotetext{
${ }^{5}$ Within a single-country cross-region context, some research demonstrates that interstate migration and spatial attributes may control to a large part the extent of government intervention in house price fluctuations. See, for instance, Hendershott (1995) and Wozniak and Murray (2012) among others.
} 
proximities make Europe a unique case to study interdependent housing market dynamics. Second, studies indicate that real estate in Europe - in all its forms - accounts for nearly $20 \%$ of economic activity. The commercial property sector alone directly contributed EUR 285 billion to the European economy in 2011, about $2.5 \%$ of the total economy and more than both the European automotive industry and telecommunications sectors combined. It directly employs over four million people, which is not only more than the car industry and the telecommunications sector, but also greater than the banking sector. ${ }^{6}$

Our study produces a number of important results. We find that the positive contribution of 'space' is consistent across model specifications. Our robustness checks, such as estimation by considering the effect of a global financial crisis and introduction of total factor productivity in the construction sector, confirm our theoretical predictions. Two broad results emerge from our exercise: first, in the absence of 'space', there is a significant over-estimation bias regarding the true impact of macroeconomic variables in housing prices. Second, there appears to be a spatial herding behavior among countries because countries, in general, share a positive and significant spatial dynamic behavior over time.

The rest of the paper is structured as follows. Section 2 presents an overview of the literature. Section 3 presents our theoretical framework and derives the empirical estimation equation. Section 4 discusses data and preliminary results leading to the analyses of the main results and sensitivity checks in Section 5. Finally, Section 6 concludes with the main findings of the paper.

\section{Literature}

The housing market is essentially spatial in nature. However, the extant research is divided with regard to their treatment of 'space' while studying the factors that govern housing prices in both intra- and inter-region contexts. Because, in our research we emphasize the instrumentality of 'space' in international housing price movements, it is important to shed light on the way 'space' has been introduced in various empirical models. Moreover, as we also underline the importance of the role of macroeconomic policy intervention in housing price fluctuations, a thorough knowledge of the existing research in this regard is also important. Keeping these contexts in mind, we briefly present an overview of the existing research from two perspectives: (i) spatial/non-spatial standpoints and (ii) international dimension of the determinants of housing prices.

\subsection{Spatial and non-spatial standpoints}

To the best of our knowledge, there is insufficient evidence on the tripartite relationship among housing prices, macroeconomic interventions and spatial dynamics. In Table 1 we present a summary of the effects of macroeconomic and other variables on housing prices with/without consideration of space.

\footnotetext{
${ }^{6}$ See European Public Real Estate Association Report: www.epra.com/.../Real_estate_in_the_real_economy__EPRA_INREV_r.
} 
Table 1: Overview of Effects of Macroeconomic and Other Variables on Housing Prices

\begin{tabular}{|c|c|c|}
\hline Variables & Effect on housing prices & Evidence from literature \\
\hline Current account balance & Negative & Arestis and Gonzalez-Martinez (2016) \\
\hline Personal disposable income & Positive & $\begin{array}{l}\text { Egert and Mihaljek (2007) } \\
\text { Posedel and Vizek (2009) } \\
\text { Kuethe and Pede (2011) } \\
\text { Arestis and Gonzalez-Martinez (2016) }\end{array}$ \\
\hline Unemployment rate & Negative & $\begin{array}{l}\text { Egert and Mihaljek (2007) } \\
\text { Kuethe and Pede (2011) }\end{array}$ \\
\hline Interest rate & Negative & $\begin{array}{l}\text { Lizieri and Satchell (1997) } \\
\text { Posedel and Vizek (2009) } \\
\text { Fereidouni et al. (2014) } \\
\text { Arestis and Gonzalez-Martinez (2016) }\end{array}$ \\
\hline Mortgage loan volumes & Positive & $\begin{array}{l}\text { Mian and Sufi (2009) } \\
\text { Favara and Imbs (2015) } \\
\text { Arestis and Gonzalez-Martinez (2016) }\end{array}$ \\
\hline $\begin{array}{l}\text { Taxation on dwellings over } \\
\text { house price }\end{array}$ & Positive & $\begin{array}{l}\text { Poterba (1992) } \\
\text { Hilbers et al. (2008) } \\
\text { Arestis and Gonzalez-Martinez (2016) }\end{array}$ \\
\hline Residential investment & Positive & Arestis and Gonzalez-Martinez (2016) \\
\hline Total factor productivity & Positive & Moro and Nuño (2011) \\
\hline
\end{tabular}

Although the spatial approach can be considered as a more informative approach for modeling housing prices-macroeconomy interactions, non-spatial approaches have been widely applied to date. Within the latter approach, researchers have frequently employed vector autoregression (VAR) models, threshold autoregressive (TAR) models, and non-spatial panel or time-series methods to study the determinants of housing prices. Using a VAR method in an international context, Stevenson (2004) investigates whether house prices experience a 'ripple effect' among countries (viz., Ireland and Northern Ireland in their investigation). ${ }^{7}$ In the case of Central and Eastern European (CEE) countries, Égert and Mihaljek (2007) demonstrate that housing prices are determined by conventional macroeconomic fundamentals. Focusing on the role of the productivity gap, Moro and Nuño (2012) argue that total factor productivity (TFP) gaps between the aggregate economy and construction sector can significantly explain the dynamics of housing prices particularly in the US and Germany.

'Space' as a determinant of housing price diffusion has been emphasized by researchers who argue that it is the central medium through which shocks move across housing markets. Indeed, expanding on the original idea of Rosen (1974), earlier research has already argued that observed

\footnotetext{
${ }^{7}$ See, for instance, Posedel and Vizek (2009) for an investigation in the context of transition and EU-15 countries.
} 
housing prices can be regarded as the implicit price of tied attributes of corresponding property in a well-defined spatial location (Basu and Thibodeau, 1998; Can, 1992). Can (1992) recognizes the importance of spatial effects in inter-regional housing markets and provides specifications and procedures to estimate such a model using characteristics of spatial dependence and spatial heterogeneity. She concludes that an estimation environment which considers both neighborhood and spatial spillover effects is superior to the one that does not allow for the role of space.

Following the outbreak of the global financial crisis (GFC) in 2008, recent works have begun to emphasize the explicit role of macroeconomic policy on housing price behaviour. Beenstock and Felsenstein (2007), for instance, examine the linkage between property transaction prices and macroeconomic policy variables by using the spatial vector autoregressive (SpVAR) model. The authors are able to detect significant interactions among four macroeconomic variables (viz., income, population, housing prices and housing stock) in nine sub-regions in Israel between 1987 and 2004. More recently, Holly et al. (2011) employ a price diffusion model to study the diffusion patterns of house price shocks in both spatial and temporal dimensions and test the validity

of a 'ripple effect' in this context. They find that the adjustment to shocks of real house price changes comes from spatially adjacent regions. The authors also demonstrate that changes in real house prices in London are directly affected by those in New York due to the close linkage these cities share with regard to the financial market characteristics. This is among many studies which demonstrate that an international transmission of a housing price shock is both a theoretical and an empirical possibility. Arestis and Gonzalez-Martinez (2016) is among the very few studies which considers international co-movements of housing prices. A study of synchronization of housing price cycles across countries can thus offer a statistical evidence of the cross-country correlation of housing prices over time.

\subsection{The international dimension: Synchronization of housing price cycles}

Indeed, while the majority of studies have focused on inter- and intra-regional dimensions of housing prices within the geographic boundary of a country, some researchers have used international context recently to show, for instance, that cross-country housing cycles are largely synchronized (particularly in the aftermath of the 2007 housing bubble in the USA). Among others, Beltratti and Morana (2010) build a factor vector autoregressive model in the case of G-7 countries, and demonstrate that there is a strong evidence of global synchronization of real house prices. This can be regarded as an indication of the linkage between international housing markets and macroeconomic conditions (Terrones and Otrok, 2004). On a similar note, Vansteenkiste and Hiebert (2011) find evidence of spillover effects of house prices among seven countries from the Euro Zone. They also find a significant long-run permanent effect of real interest rates on real house prices. In a related study, Bagliano and Morana (2012) apply a factor VAR framework incorporating 50 countries to study both within-US and international transmission mechanisms of financial and macroeconomic shocks, and examine the effect of US house prices on both advanced and emerging economies. More recently, Cesa-Bianchi (2013) provide evidence that real house 
price returns are strongly correlated across both advanced and emerging economies.

Very recently, Fereidouni et al. (2016) examine the dynamic interactions of housing price among major economic regions in Malaysia and Singapore. The authors find that shocks to housing prices not only move within a single country but also move across borders. The results are consistent with the theory of 'ripple effect'. Arestis and Gonzalez-Martinez (2016) are among the first to spell out a clear linkage between macroeconomic fundamentals and housing price dynamics. Based on the dataset of 17 OECD countries spanning the period 1970-2013, the authors find evidence of correlation among countries' house prices, which they attribute to the co-movement in the fundamental factor of supply and demand functions of housing markets as well as the state of macroeconomic policy in a country. They find that house prices and current account imbalances are positively correlated as these two variables are driven by common macroeconomic fundamentals. While the critical interplay of macroeconomic adjustments is important in understanding international housing price movements, the omission of 'space' as a medium of diffusion of policy shocks can lead to an over-(under-)emphasis of the role of macroeconomic policy in housing price determination. In light of this argument, an empirically testable theoretical construct can help us intertwine 'space' in the macroeconomy-housing price relationship. We present this as an analytical model below.

\section{Theoretical construct and estimation}

\subsection{Theoretical construct}

To guide our empirical construct (to be presented in the next section), we need to build a testable theoretical model that embeds spatial spillover effects within a housing price-macroeconomic interaction setting. We combine the interface literature of macroeconomics and economic geography with real estate theory to build an analytical model. Our strategy is as follows. First, we present briefly the classical housing-market equilibrium model and study its properties leading to the introduction of 'space' in the housing production function. Second, we build our empirical equation following the theoretical construct and discuss various estimation issues.

\subsubsection{Classical housing-market equilibrium}

Concerning the role of macroeconomic (policy) variables in housing market fluctuations, Hilbers et al. (2008) classify policies that may affect house prices in four types: fiscal (for rents and income), monetary (for interest rates), structural (supply and demand for housing) and prudential (for the financing of the housing market). We follow Arestis and Gonzalez-Martinez (2016) and then extend their framework to a spatial setting.

Let us denote the equilibrium housing prices $\left(h p i^{*}\right)$ as a solution to the demand-supply system for housing prices. This equilibrium is an outcome of the forces within a competitive housing market. The demand equation for housing $\left(H P_{D}\right)$ is supposed to be determined by seven factors, viz., 
house prices $(h p i)$, current account balance $(c b)$, personal disposable income $(p d i)$, unemployment rate $(u r)$, real interest rate of house buyers $\left(\right.$ rir $\left._{d}\right)$, mortgage loan volumes (credit) and taxation on dwellings over house prices $(\operatorname{tax})$.

$$
H P_{D}=f_{D}\left(h p i^{-}, c b^{-}, p d i^{+}, u r^{-}, \operatorname{rir}_{d}^{-}, \text {credit }^{+}, \operatorname{tax}^{-}\right)
$$

Following convention, housing demand $\left(H P_{D}\right)$ is negatively related to house prices $(h p i)$, current account balance $(c b)$, unemployment rate $(u r)$, real interest rate of house buyers $\left(\right.$ rir $\left._{d}\right)$ and taxation on dwellings over house prices $(\operatorname{tax})$. Moreover, $H P_{D}$ is also assumed to be positively determined by personal disposable income ( $p d i)$ and mortgage loan volumes (credit).

Similarly, the housing supply equation is assumed to be determined by three factors, viz., house prices $(h p i)$, real interest rate for housing development $\left(\right.$ rir $\left._{s}\right)$ and residential investment (rri). Thus,

$$
H P_{S}=f_{S}\left(h p i^{+}, r i r_{s}^{-}, r r i^{+}\right)
$$

Following arguments in the literature, we assume that house prices ( $h p i)$ and residential investment ( $r r i)$ exert positive effects on real estate supply. In contrast, the supply is negatively influenced by real interest rate of house developers $\left(\mathrm{rir}_{\mathrm{s}}\right)$. Hence, under the hypothesis of a fully competitive market equilibrium, the market clearing condition can be obtained by equating both demand function (1) and supply function (2), which gives rise to the following housing-market equilibrium ${ }^{8}$ :

$$
h p i^{*}=f_{h p i}\left(c b^{-}, p d i^{+}, u r^{-}, r i r^{-}, c r e d i t^{+}, t a x^{-}, r r i^{-}\right)
$$

In the equilibrium, personal disposable income ( $p d i)$ and mortgage loan volumes (credit) are expected to exert a positive effect on housing prices, while current account balance $(c b)$, unemployment rate (ur), real interest rate (rir), taxation on dwellings over house prices (tax) and residential investment (rri) leave a negative impact on housing prices.

\subsubsection{Spatial spillover model with macroeconomic interaction}

From the above it is now clear that - under a competitive market condition - macroeconomic policy adjustment can leave notable effects on housing prices. However, such a market condition does not allow persistence of frictions that may arise in the market due to incomplete information, spatial interdependence, stochastic shocks and imperfect market structure. To accommodate these realistic possibilities, the above competitive market equilibrium can be extended. To achieve this, we present the following framework.

Assume that there are $N$ countries, indexed by $i=1, \ldots, N$. We model each country's housing production with respect to three factors: (i) $M$ (general macroeconomic policy variables, such as current account balance and unemployment rate, etc.) (ii) $H D$ (other policy instruments directly

\footnotetext{
${ }^{8}$ Following Arestis and Gonzalez-Martinez (2016), we use, for the sake of simplicity, only one real interest rate (rir) in the credit market. This is relevant to both house buyers and builders/developers. Detailed descriptions and sources for all variables mentioned above can be seen in Table 2. Moreover, the theoretical justifications of signs of all incorporated independent variables have been discussed in details in Arestis and Gonzalez-Martinez (2016).
} 
controlled by monetary and fiscal authorities, such as taxation on property over housing prices and real interest rate, etc.). Our third factor (iii) is $D_{i j}$ (spatial attributes), which we introduce in the housing production shortly. Our basic housing production function is presented as follows:

$$
h p i_{i}(t)=A_{i}(t)\left(M_{i}(t)^{\alpha} H D_{i}(t)^{1-\alpha}\right)^{\gamma}
$$

The function $A_{i}(t)$ describes the aggregate level of productivity of a country $i . \gamma$ measures the extent of returns to scale, whereas $\alpha$ delineates the importance of general macroeconomic policy factors in housing prices. We express the function $A_{i}(t)$ as:

$$
A_{i}(t)=\Gamma(t)\left(m h_{i}(t)\right)^{\delta} \prod_{j \neq i}^{N} A_{j}(t)^{\beta D_{i j}}
$$

The dynamics of $A_{i}(t)$ depend on three terms. First, we suppose that a part of the productivity growth is exogenous and identical to all countries: $\Gamma(t)=\Gamma(0) e^{\mu t}$ where $\mu$ is the constant rate of growth and is independent of the growth of $M$ and $H D$. Second, we assume that each country's $A_{i}(t)$ increases with the aggregate level of general macroeconomic policy variables $\left(M_{i}\right)$ per other policy instruments $\left(H D_{i}\right)$ available in the country. This gives rise to $m h=M_{i} / H D_{i}$ and denotes the proportion of general macroeconomic policy variations with respect to other policy instruments determining housing prices. The parameter $\delta$, with $0<\delta<1$, describes the strength of home externalities generated by the macroeconomic policy adjustments. Moreover, we introduce knowledge spillover from macroeconomic policy adjustment and assume that such a strategy not only improves sound macroeconomic conditions but also increases the level of knowledge for all investors in the economy through knowledge spillover. However, there is no reason to constrain these externalities within the barriers of a country. In fact, we can suppose that the external effect of knowledge embodied in macroeconomic adjustment in one country extends beyond its border but does so with diminished intensity because of spatial friction generated by distance or border effect for instance. Indeed, in a highly interdependent world, any policy adjustment followed in one country becomes a common knowledge in other countries. Depending on the extent of geographic and relational (i.e., economic) proximities among countries, then this knowledge transmission can give rise to a hyperbolic effect of policy intervention over time.

This idea is modeled by the third term in equation (5). The particular functional form we assume for this term in a country, $i$, is a geometrically weighted average of the stock of knowledge of its neighbors denoted by $j$. Housing price interdependence (across economies) is represented by the parameter $0<\beta<1$, where it is assumed that the interdependence is not perfect because of the presence of possible frictions between the home country $i$ and foreign countries $j \neq i, j=1, \ldots, N$. The relationship between $i$ and $j$ can be represented by $D_{i j}$; the higher is the distance between $i$ and $j$, the smaller is the value of $D_{i j}$ and vice versa. Elements of $D_{i j}$ are assumed to be positive and $D_{i j}=0$ if $i=j$. Moreover, $D_{i j}$ is non-stochastic and finite so that $0 \leq D_{i j} \leq 1$ and $\sum_{j \neq i}^{N} D_{i j}=1$. This hypothesis allows us to form relative spatial connectivity among all countries. Moreover, it 
avoids spatial scale effects and explosive growth of housing prices. The more a given country $i$ is connected to its neighbors, the higher $D_{i j}$ is and the more country $i$ benefits from spatial externalities or spillovers.

Thus, international macroeconomic and housing market interdependence implies that countries cannot be analyzed in separation but must be analyzed as an interdependent system. Therefore, we can rewrite function (5) in matrix form (see Appendix A for detailed derivation):

$$
A=\Gamma+\delta m h+\beta D A
$$

with $A$ the $(N \times 1)$ vector of the logarithms of the level of productivity $\left(A_{i}\right)$, where $i=1, \ldots, N . m h$ is the $(N \times 1)$ vector of the logarithms of the aggregate level of macroeconomic variables $\left(M_{i}\right)$ per other common attributes $\left(H D_{i}\right) . D$ is the $(N \times N)$ Markov-matrix with spatial friction parameters $D_{i j}$. We can resolve equation (6) for $A$, if $\beta \neq 0$ and if $1 / \beta$ is not an eigenvalue of $D$ :

$$
A=(I-\beta D)^{-1} \Gamma+\delta(I-\beta D)^{-1} m h
$$

We can develop equation (7). Assuming $|\delta|<1$, we can regroup terms to obtain:

$$
A=\frac{1}{(1-\beta)} \Gamma+\delta m h+\delta \sum_{r=1}^{\infty} \beta D^{(r)} m h
$$

where $D^{(r)}$ is the matrix $D$ to the power, $r$. For country $i$, then we have

$$
A_{i}(t)=\Gamma^{\frac{1}{(1-\beta)}}(t) m h_{i}^{\delta}(t) \prod_{j=1}^{N} m h_{j}^{\delta} \sum_{r=1}^{\infty} D_{i j}^{(r)}(t)
$$

The level of productivity in a country $i$ now depends on its own level of $m h$ and on the level of $m h$ in its neighborhood. Replacing equation (9) in the housing market production function (4) and assuming $\gamma=1$, we can write the spatial housing production function as

$$
h p i_{i}(t)=\Gamma^{\frac{1}{(1-\beta)}}(t) m h_{i}^{u_{i i}}(t)+\prod_{j \neq i}^{N} m h_{j}^{u_{i j}}(t)
$$

where $u_{i i}=\alpha+\delta\left(1+\sum_{r=1}^{\infty} \beta^{r} D_{i j}^{(r)}\right)$ and $u_{i j}=\left(\delta \sum_{r=1}^{\infty} \beta^{r} D_{i j}^{(r)}\right)$.

The terms $D_{i j}^{(r)}$ are the elements of row $i$ and the column $j$ of the matrix $D$ to the power of $r$. This model implies spatial heterogeneity in the parameters of the housing production function. In the absence of externalities, i.e. when $\delta=0$, we have $u_{i i}=\alpha$ and $u_{i j}=0$, so that the housing production function takes the conventional form as in (4).

Based on the properties described above, we state the following proposition.

Proposition 1. If equilibrium housing production is given by $h p i_{i, t}^{*}=G\left(M_{i, t} ; H D_{i, t} ; f_{i}\left(D_{t}(i, j)\right)\right.$, then spatial frictions (i.e. the function $f_{i}\left(D_{t}(i, j)\right.$ ) determine the extent to which macroeconomic policy variables 
affect housing price variations across countries under the hypothesis of fully competitive market equilibrium.

The proof is straightforward and follows from the analytical equations above. In particular, based on the assumption that spatial frictions affect housing price behavior in countries $(i, j)$, the effect of macroeconomic variations will depend upon the strength of $\beta$. This is simply because a higher $\beta$ represents greater interdependence, and this would ensure faster movements of macroeconomic shocks across borders. Hence, interdependent economies will experience greater and more similar effects of shocks than would have been the case under an atomistic environment. The analytical model presented above needs to be estimated. Recalling that ours is a spatio-temporal case, we discuss relevant empirical methods in the dynamic spatial panel framework in the next section.

\subsection{Estimation}

\subsubsection{Model selection}

We can now use equation (10) in an extended form to present our empirical model. The expansion of equation (10) in our context is motivated by the presence of bounded rationality in house buyers and suppliers, external uncertainty, incomplete information and imperfect market structure. These together can create excess demand or laggard supply in the real estate market. Therefore, the classical assumption of a fully competitive equilibrium market (that is, housing demand equals corresponding supply in equation (3)) is no longer valid. To set our empirical construct free from the strict limitations of a fully competitive equilibrium, we introduce a spatio-temporal partial adjustment model. ${ }^{9}$ Indeed, the dynamic spatial panel model provides a mechanism that admits the existence of disequilibrium variations, i.e. it enables us to recognize and interpret the disequilibrium shocks for the dependent variable via its dynamic components, i.e. temporal and spatio-temporal lags. We incorporate these features in equation (10) for an empirical specification of the model in the form of dynamic spatial panel regression:

$$
\begin{gathered}
h p i_{i t}=\alpha+\beta h p i_{i t-1}+\gamma \sum_{j=1}^{N} W_{i j} h p i_{i t}+\rho \sum_{j=1}^{N} W_{i j} h p i_{i t-1}+\sum_{k=1}^{K} X_{i t} \zeta_{k}+\sum_{k=1}^{K} \sum_{j=1}^{N} W_{i j} X_{j k t} \eta_{k}+\theta_{i}+\nu_{t}+\pi_{i t} \\
\pi_{i t}=\psi \sum_{j=1}^{N} W_{i j} \pi_{i t}+\varepsilon_{i t} \\
i=1, \ldots, N ; t=1, \ldots, T ; k=1, \ldots, K ; i \neq j
\end{gathered}
$$

Three spatial interaction features are present in equations (11) and (12): (i) endogenous interactions $\left(\sum_{j=1}^{N} W_{i j} h p i_{i t}\right)$, (ii) exogenous interactions $\left(\sum_{k=1}^{K} \sum_{j=1}^{N} W_{i j} X_{j k t}\right)$ and (iii) residual interactions $\left(\sum_{j=1}^{N} W_{i j} \pi_{i t}\right)$. $\alpha$ is the constant parameter vector; $\gamma, \eta$ and $\psi$ are coefficients for these spatial dependencies, respectively. Also, $h p i_{i t}$ denotes house prices (our dependent variable) and $X_{i t}$

\footnotetext{
${ }^{9}$ See LeSage and Pace (2009) for discussion on the properties of the spatio-temporal spatial adjustment model.
} 
denotes the vector of independent variables. $\theta_{i}$ and $\nu_{t}$ refer to space-specific and time-periodspecific effects. ${ }^{10}$ Error terms $\left(\varepsilon_{t}\right)$ are identically and independently distributed $\left(\varepsilon_{t} \sim N\left(0, \sigma^{2} I_{N}\right)\right)$. Besides, due to the requirements of parameter identification (Manski, 1993), the spatial interactions (i.e. exogenous, endogenous and residual interactions) cannot be presented simultaneously (at least one interaction needs to be removed from the specification). Hence, distinct specifications of the spatial panel model can be derived by considering different spatial dependencies (Elhorst, 2010); (i) spatial autoregressive model (SAR) by considering spatial endogenous dependencies $(\eta=\psi=0)$, (ii) the spatial Durbin model (SDM) by considering both spatial endogenous dependencies and spatial exogenous dependencies $(\psi=0)$, and (iii) the spatial error model (SEM) by merely considering spatial residual dependencies $(\gamma=\eta=0)$, respectively. In addition, the static spatial panel model can be extended to include dynamic component by introducing both a temporal lag $\left(Y_{i t-1}\right)$ and temporally spatial lag $\left(W_{i j} h p i_{i t-1}\right)$ of the dependent variable (Debarsy et al., 2012). ${ }^{11}$

In view of the properties of various spatial panel models described above, our preferable specification is the dynamic spatial Durbin model (SDM). The dynamic SDM with fixed effects can be derived by controlling the coefficient $\psi$ in (12) to be zero:

$$
\begin{gathered}
h p i_{i t}=\alpha+\beta h p i_{i t-1}+\gamma \sum_{j=1}^{N} W_{i j} h p i_{i t-1}+\rho \sum_{j=1}^{N} W_{i j} h p i_{i t}+\sum_{k=1}^{K} X_{i t} \zeta_{k}+\sum_{k=1}^{K} \sum_{j=1}^{N} W_{i j} X_{j k t} \eta_{k}+\theta_{i}+\nu_{t}+\varepsilon_{i t} \\
i=1, \ldots, N ; t=1, \ldots, T ; k=1, \ldots, K ; i \neq j
\end{gathered}
$$

Although the spatial autoregressive model (SAR) is the most widely used spatial panel specification, it is useful to add elements of spatial exogenous interactions - in addition to spatial endogenous interactions - in the spatial Durbin model (SDM) setting (Lee and Yu, 2016). We note below its key advantages in relation to our empirical analyses. ${ }^{12}$

First, it complies with the identification requirements as noted in Manski (1993) and only suffers the minimum cost of exclusion of spatial residual interactions compared with other spatial models. Second, SDM offers unbiased and consistent estimation irrespective of the real datagenerating process (either SAR or SEM) (Elhorst, 2010). Third, it distinguishes the explanatory power of the exogenous variables not only within spatial boundaries (direct effect), but also across spatial contiguous locations (indirect effect). Elhorst (2010) demonstrates that the non-spatial model

\footnotetext{
${ }^{10}$ Both the effects can be regarded as either fixed effects or random effects. However, whether a random effects model is an appropriate specification remains controversial in spatio-temporal estimation (Elhorst, 2012). In principle, a random effects model will only be preferable if data are drawn randomly from the population and the number of the spatial units $(N)$ is large. Moreover, the strict restriction that random variables and error terms are independent is hard to comply with in reality. Elhorst (2012) particularly demonstrates that the fixed effects model is superior to the random effects model in the case of the spatial panel model, given that two prerequisites are satisfied, viz., large time period $(T)$ and no bias of variable omissions. We will demonstrate later that the spatial panel model with fixed effects is a better fit for our data.

${ }^{11}$ We provide a further check on whether both $Y_{i t-1}$ and $W_{i j} Y_{i t-1}$ are jointly equal to zero. The likelihood ratio (LR) test is used for the purpose to investigate whether the dynamic spatial panel model is preferable in our empirical investigation.

${ }^{12}$ Other notable advantages of SDM in comparison to other spatial panel specifications (viz., SAR and SEM) have been well documented (LeSage and Pace, 2009).
} 
seriously biases the coefficient estimations, and is unable to shed light on the indirect effects (spatial spillover effects) from spatially neighboring units. Fourth, SDM enables us to account for not only spatial dependencies but also spatial heterogeneity across spatial locations by incorporating spatially lagged dependent variable and spatially lagged independent variables, respectively. Fifth, in terms of the endogeneity problem (which is typical in an empirical context such as ours), the SDM helps ameliorate endogeneity issues and omitted variable bias. ${ }^{13}$

In addition, in terms of the comparison of spatial model specifications, Lee and Yu (2016) show that disregarding Durbin terms (spatial exogenous interactions) leads to serious estimation biases, while adding irrelevant Durbin terms only leads to indistinct efficiency loss. This is consistent with the theoretical viewpoint discussed above in that SDM is superior to other spatial models. In our estimation, we employ a series of likelihood ratio (LR) tests as in Elhorst (2010) to examine if the SDM is our preferable specification among a set of competitive spatial panel models.

\subsubsection{Endogeneity concerns and estimation strategy}

Our empirical specification might suffer from possible endogeneity bias; for instance, housing prices might be correlated with other unobserved economic variables.

A strategy to overcome such a bias is necessary to guarantee consistent and unbiased estimates of the parameters (For discussion, see Fingleton and Le Gallo (2010)). Particularly, in our context, this can be resolved by adding both contemporaneous spatial endogenous and exogenous lags to the estimated model. In terms of the parameter identification, Lee and Yu (2016), however, doubt the validity of the identification strategy in the dynamic SDM by arguing that the effect of spatial lag of the dependent variable $\left(W Y_{t}\right)$ cannot be identified in the presence of both spatial independent $\left(W X_{t}\right)$ and spatially weighted temporal lag of the dependent variables $\left(W Y_{t-1}\right)$ (Anselin et al., 2008). Instead, they demonstrate that model parameters in the dynamic SDM are identifiable by either $G M M$ or quasi maximum likelihood $(M L)$.

The above discussions point at the importance of choosing a correct estimation method for dynamic SDM specification in equation (13). The choice needs to be made among ordinary least squares $(O L S)$, the maximum likelihood $(M L)$, and the partial derivative $(P D)$ methods. To lend support to our choice, we follow the theoretical arguments in Anselin (1988) and note that $O L S$ estimates are biased and inconsistent in the presence of the lagged dependent variable (irrespective of whether this is a spatial, temporal or spatio-temporal model). We can use $O L S$ as the benchmark specification so that comparison of coefficients from the more robust estimation procedures can be made. Our preferable estimation technique is the maximum likelihood method $(M L)$ as this is a well-known estimation method defined for a well-behaved likelihood function of the relationship among dependent and explanatory variables. ${ }^{14}$ Moreover, the $M L$ method is

\footnotetext{
${ }^{13}$ Fingleton and Le Gallo (2010) point out that the particular endogeneity problem due to omitted variables can be accounted for by the SDM specification due to the inclusion of both spatial lagged dependent and independent variables.

${ }^{14}$ This method has been extensively applied in the estimation of the spatial panel model (see, for instance, Bao and Ullah (2007); Elhorst and Fréret (2009); Koroglu and Sun (2016); Lee (2004); Lee and Yu (2016); Ord (1975)).
} 
known to overcome the problem of the imprecise and inappropriate coefficients produced by the $O L S$ method while estimating the (dynamic) spatial panel model (see, for instance, Anselin, 1988; Anselin and Hudak, 1992; Elhorst, 2003; Lee, 2004; Yu et al., 2008, among others). Furthermore, the $M L$ method applied to our SDM specification provides us with consistent estimates of coefficients when numbers of both time periods and spatial units are large (Yu et al., 2008). ${ }^{15}$ Bias corrections of the aforementioned estimated coefficients can also be measured and can be used to adjust the deviations in the initial ML estimators. In addition, estimating the spatial panel model by the $M L$ technique allows practitioners to investigate if the specific group of estimated coefficients are jointly significant by using the likelihood ratio (LR) test. This imposing property of the $M L$ method is important for identifying the right model specification, determining thereby if the selected spatial panel model (i) is static or dynamic and (ii) SAR, SDM or SEM.

An alternative method to derive consistent estimates of spatial panel models is based on the instrumental variables regression $(I V / 2 S L S)$ approach. In general, the estimators of either the $M L$ or the $I V / 2 S L S$ for the spatial panel model can be reliable as long as specific assumptions of each method are satisfied, viz., consistent and asymptotically distributed estimators for the $M L$ method (Kelejian and Prucha, 1998), and correlated explanatory variables for the $I V / 2 S L S$ method (Lee, 2004). We do not employ the $I V / 2 S L S$ method in our estimation because despite its potential to eliminate endogeneity, it still fails to account for issues such as the effects of additional endogenous variables in the regression (Fingleton and Le Gallo, 2010). Moreover, the specification of the SDM in Fingleton and Le Gallo (2010) not only contains spatial endogenous and exogenous interactions but also adds spatial residual interactions, which may further cause the problem of parameter identification raised by Manski (1993). Finally, in contrast with $M L$ method, the $I V / 2 S L S$ method could not lend to the joint significance test of the regressors (Kelejian and Prucha, 1998). For these reasons, we choose the $M L$ estimation method for our SDM specification.

The literature also suggests that the partial derivative $(P D)$ estimation of the SDM parameters can shed new light on interpreting different types of parameters (direct/indirect effects of independent variables). Also, it can test the hypothesis of whether spatial spill-over effects exist in the tested empirical specification. Distinct from the classical point estimates, the $P D$ method overcomes the typical problem of invalid comparisons of point estimates from various spatial regression, implying that changing model specifications might lead to heterogeneous inferences (see, LeSage and Pace (2009), for exhaustive discussions of the properties of this method). In addition, the $P D$ method provides us with both long-term and short-term direct/indirect effects of independent variables.

In terms of a location, the direct effect refers to the averaged (own-partial) derivative of $Y$ with respect to explanatory variables, $X$, from the same location. The indirect effect, also termed the

\footnotetext{
${ }^{15} \mathrm{Yu}$ et al. (2008) build a bias-corrected quasi maximum-likelihood ( $\left.Q M L\right)$ estimator to estimate a dynamic spatial panel model with spatial fixed effects. This estimator can be constructed by the Stata command "xsmle" (Belotti et al., 2017). Moreover, "xsmle" treats the dynamic terms, viz., temporally spatial lagged dependent variable $\left(W_{i j} Y_{i t-1}\right)$ and temporally lagged dependent variable $\left(Y_{i t-1}\right)$, as the predetermined variables. A bias-corrected ML technique (i.e., quasi maximum likelihood (QML)) can be used for the purpose (Yu et al., 2008). For simplicity, we use the terms $M L$ and $Q M L$ interchangeably throughout the paper.
} 
spatial spillover effect, refers to the averaged (cross-partial) derivative of $Y$ with respect to explanatory variables, $X$, from the neighboring locations. According to Blanchard et al. (1992) and De Groot and Elhorst (2010), by using the PD method, it is possible to characterize the error correction process so that one can envisage how an economy adjusts back to its long-term equilibrium over time. To summarize, with respect to the estimation method of the dynamic SDM, we employ the $M L$ method to estimate our main model. It will also help us compare our work with the existing literature which invariably applies the $M L$ method for estimation. In addition, the $P D$ can be regarded as an alternative method to check whether direct/indirect effects of the independent variables obtained from the $M L$ estimation are robust or not.

A challenge concerning SDM is the interpretation of the dynamic terms in the model. Tao and $\mathrm{Yu}$ (2012) stress the necessity to add a spatially-weighted temporal lag of the dependent variable $\left(W Y_{t-1}\right)$ in the SDM model because this term can account for 'either policy adjustments or intertemporal budget constraints'. Its omission may result in serious bias in estimations. The general empirical finding is that this $W Y_{t-1}$ can give rise to an estimated negative coefficient, which is sometimes hard to lend a sensible empirical interpretation to. Following Tao and Yu (2012), the negative coefficient may arise when the coefficients of both contemporaneous spatial $\left(W Y_{t}\right)$ and temporal $\left(Y_{t-1}\right)$ lags of the dependent variable are jointly positive. In our empirical investigation, such a situation may arise. We provide both statistical and empirical interpretations of this result.

\section{Data characteristics and preliminary observations}

\subsection{Data characteristics}

Our empirical investigation uses annual time-series data for 16 European countries and covers a period of three decades (1985-2015). ${ }^{16}$ The dependent variable is house prices ( $\left.h p i\right)$, while the independent variables include two types of macroeconomic factors. The first one is the general macroeconomic policy factors, which summarize macroeconomic conditions, such as the current account balance $(c b)$, personal disposable income $(p d i)$, unemployment rate $(u r)$, mortgage loan volumes (credit) and residential investment (rri). The second one concerns other policy variables, which represent macroeconomic interventions directly enforced by regulated bodies in respective countries, viz., real interest rate (rir) and taxation on dwellings over house prices (tax). In Table 2 , we provide the descriptions of the variables and their sources.

In Figure 1, we present an average trend of house price movements across the 16 European countries. The value in each time period is calculated as the averaged growth of house price indices across economies. There is evidence of a cyclical pattern of house prices in the last three decades; the housing prices experienced a peak in 1989, a marked drop in 1993, and a recovery that continued until 2000. The boom and bust of cyclical behaviors of house prices can also be

\footnotetext{
${ }^{16}$ The 16 European countries include Austria, Belgium, Denmark, Finland, France, Germany, Ireland, Italy, Luxembourg, the Netherlands, Norway, Portugal, Spain, Sweden, Switzerland, and the UK. Our choice of countries is governed by the identification of common geographic and economic borders and availability of continuous data.
} 
Table 2: Data Description

\begin{tabular}{|c|c|c|}
\hline Variables & Descriptions & Data Sources \\
\hline Current account balance $(c b)$ & $\begin{array}{l}\text { Balance on current transactions with the } \\
\text { rest of the world ( } \% \text { of GDP) }\end{array}$ & AMECO Databank \\
\hline Personal disposable income ( $p d i)$ & $\begin{array}{l}\text { Disposable income per capita of working-age } \\
\text { population }(2005=100)\end{array}$ & $\begin{array}{l}\text { Federal Reserve Bank of Dallas \& } \\
\text { AMECO Databank }\end{array}$ \\
\hline Real interest rate $(r i r)$ & Real long-run interest rate, deflator GDP & $\begin{array}{l}\text { AMECO Databank \& International } \\
\text { Financial Statistics of IMF }\end{array}$ \\
\hline Mortgage loan volumes (credit) & Domestic credit to private sector ( $\%$ of GDP) & $\begin{array}{l}\text { Word Development Indicators } \\
\text { of the World Bank }\end{array}$ \\
\hline
\end{tabular}

Figure 1: The Cross-country Averaged Growth of House Prices (hpi) $(\mathbf{2 0 0 5 = 1 0 0 )}$

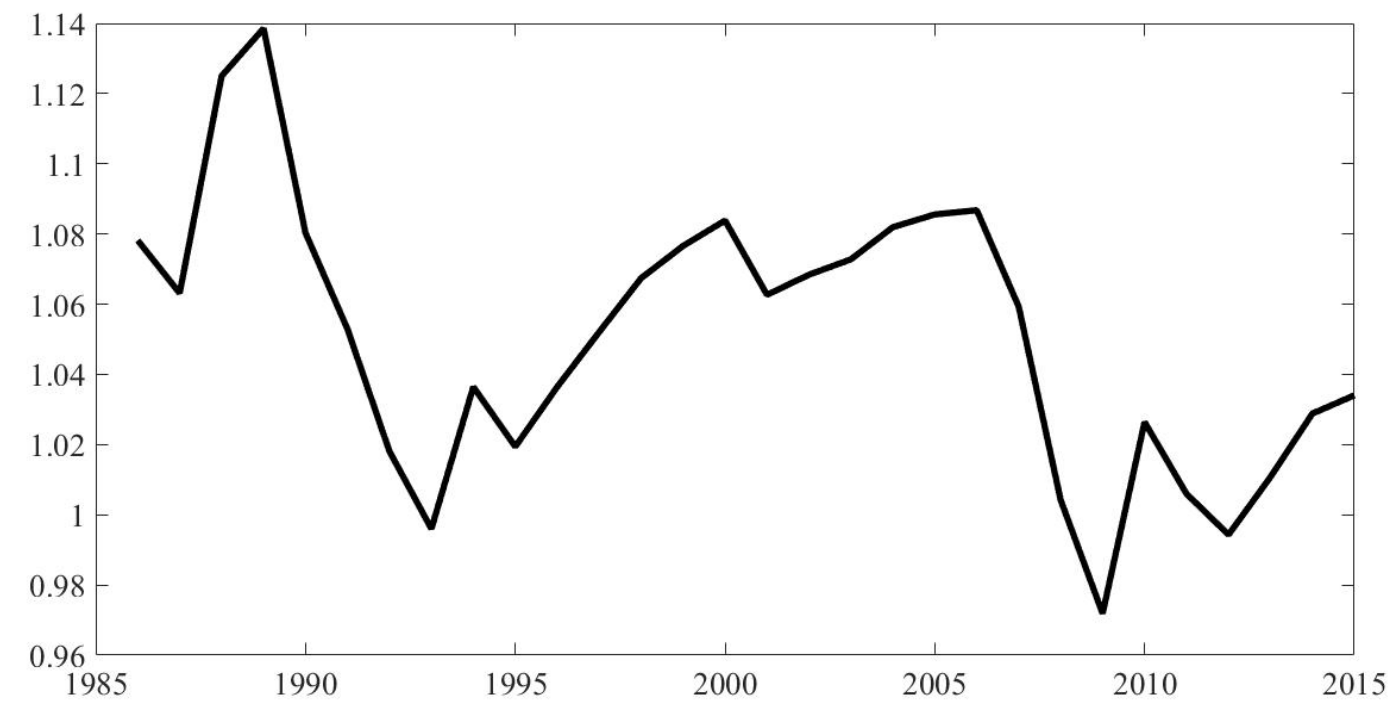

Note: (i) Averaged growth (growth) is calculated as growth $=\left(\sum_{i=1}^{N} h p i_{i t} / h p i_{i t-1}\right) / N$. (ii) the data time period is from 1986 to 2015.

observed in the following decade (2001-2009). These facts lead us to conclude that housing cycles in our data lasts for about 10 -years. In addition, the lowest visible prices in 2009 capture the negative impact of the global financial crisis.

In Table 3 we present descriptive statistics. The mean $h p i$ for the 16 European countries is 78.963 with a standard deviation of 36.287. Austria presents the largest mean value of $h p i$ (105.507) as well as a relatively high standard deviation (41.622). Germany exhibits the third largest $h p i$ and 
Table 3: Descriptive Statistics: Mean and Dispersion of Housing Prices and its Determinants

\begin{tabular}{|c|c|c|c|c|c|c|c|c|c|}
\hline Variables & Austria & Belgium & Denmark & Finland & France & Germany & Ireland & Italy & Luxembourg \\
\hline hpi & $\begin{array}{l}105.507 \\
(41.622)\end{array}$ & $\begin{array}{c}81.159 \\
(40.488)\end{array}$ & $\begin{array}{c}73.711 \\
(31.711)\end{array}$ & $\begin{array}{c}78.615 \\
(32.990)\end{array}$ & $\begin{array}{c}74.395 \\
(34.146)\end{array}$ & $\begin{array}{c}99.257 \\
(11.040)\end{array}$ & $\begin{array}{c}54.992 \\
(35.594)\end{array}$ & $\begin{array}{c}73.027 \\
(27.848)\end{array}$ & $\begin{array}{c}72.389 \\
(38.137)\end{array}$ \\
\hline $\mathrm{cb}$ & $\begin{array}{c}-1.589 \\
(1.732)\end{array}$ & $\begin{array}{c}2.979 \\
(1.688)\end{array}$ & $\begin{array}{c}2.638 \\
(2.810)\end{array}$ & $\begin{array}{c}1.364 \\
(4.028)\end{array}$ & $\begin{array}{c}-0.372 \\
(1.629)\end{array}$ & $\begin{array}{c}-0.628 \\
(7.704)\end{array}$ & $\begin{array}{c}-0.268 \\
(2.871)\end{array}$ & $\begin{array}{c}-0.316 \\
(1.689)\end{array}$ & $\begin{array}{l}10.731 \\
(3.864)\end{array}$ \\
\hline pdi & $\begin{array}{c}86.607 \\
(26.246)\end{array}$ & $\begin{array}{c}88.117 \\
(23.044)\end{array}$ & $\begin{array}{c}86.364 \\
(25.512)\end{array}$ & $\begin{array}{c}87.055 \\
(30.133)\end{array}$ & $\begin{array}{c}86.674 \\
(22.190)\end{array}$ & $\begin{array}{c}88.948 \\
(21.622)\end{array}$ & $\begin{array}{c}71.555 \\
(31.517)\end{array}$ & $\begin{array}{c}81.119 \\
(23.045)\end{array}$ & $\begin{array}{c}86.636 \\
(28.847)\end{array}$ \\
\hline ur & $\begin{array}{c}4.413 \\
(0.800)\end{array}$ & $\begin{array}{c}8.261 \\
(1.076)\end{array}$ & $\begin{array}{c}6.035 \\
(1.500)\end{array}$ & $\begin{array}{c}8.855 \\
(3.540)\end{array}$ & $\begin{array}{c}9.145 \\
(0.962)\end{array}$ & $\begin{array}{c}7.887 \\
(1.685)\end{array}$ & $\begin{array}{l}10.726 \\
(4.701)\end{array}$ & $\begin{array}{c}9.403 \\
(1.669)\end{array}$ & $\begin{array}{c}3.494 \\
(1.425)\end{array}$ \\
\hline rir & $\begin{array}{c}3.153 \\
(1.753)\end{array}$ & $\begin{array}{c}3.538 \\
(2.001)\end{array}$ & $\begin{array}{c}3.514 \\
(2.711)\end{array}$ & $\begin{array}{c}3.816 \\
(3.001)\end{array}$ & $\begin{array}{c}3.663 \\
(2.037)\end{array}$ & $\begin{array}{c}2.608 \\
(1.734)\end{array}$ & $\begin{array}{c}3.914 \\
(3.646)\end{array}$ & $\begin{array}{c}3.669 \\
(1.921)\end{array}$ & $\begin{array}{c}2.602 \\
(3.216)\end{array}$ \\
\hline credit & $\begin{array}{l}92.544 \\
(8.700)\end{array}$ & $\begin{array}{c}57.498 \\
(15.904)\end{array}$ & $\begin{array}{l}106.596 \\
(67.452)\end{array}$ & $\begin{array}{c}72.535 \\
(15.391)\end{array}$ & $\begin{array}{l}85.490 \\
(7.849)\end{array}$ & $\begin{array}{c}94.643 \\
(12.384)\end{array}$ & $\begin{array}{c}83.172 \\
(40.287)\end{array}$ & $\begin{array}{c}66.660 \\
(16.294)\end{array}$ & $\begin{array}{c}88.965 \\
(13.641)\end{array}$ \\
\hline $\operatorname{tax}$ & $\begin{array}{l}20.924 \\
(7.203)\end{array}$ & $\begin{array}{c}82.246 \\
(13.360)\end{array}$ & $\begin{array}{c}77.958 \\
(12.717)\end{array}$ & $\begin{array}{l}39.014 \\
(4.531)\end{array}$ & $\begin{array}{l}114.274 \\
(15.529)\end{array}$ & $\begin{array}{l}26.002 \\
(5.142)\end{array}$ & $\begin{array}{l}103.385 \\
(26.969)\end{array}$ & $\begin{array}{c}68.473 \\
(20.962)\end{array}$ & $\begin{array}{l}239.378 \\
(41.528)\end{array}$ \\
\hline rri & $\begin{array}{l}10.418 \\
(2.832)\end{array}$ & $\begin{array}{l}14.697 \\
(6.125)\end{array}$ & $\begin{array}{c}7.978 \\
(3.429)\end{array}$ & $\begin{array}{l}8.076 \\
(2.973)\end{array}$ & $\begin{array}{c}87.818 \\
(30.816)\end{array}$ & $\begin{array}{l}122.545 \\
(34.271)\end{array}$ & $\begin{array}{c}7.141 \\
(6.936)\end{array}$ & $\begin{array}{c}64.141 \\
(18.099)\end{array}$ & $\begin{array}{c}0.803 \\
(0.402)\end{array}$ \\
\hline Variables & Netherlands & Norway & Portugal & Spain & Sweden & Switzerland & UK & Total & \\
\hline hpi & $\begin{array}{c}67.617 \\
(32.751)\end{array}$ & $\begin{array}{c}87.730 \\
(45.622)\end{array}$ & $\begin{array}{c}75.464 \\
(23.623)\end{array}$ & $\begin{array}{c}62.313 \\
(32.595)\end{array}$ & $\begin{array}{c}83.161 \\
(42.718)\end{array}$ & $\begin{array}{l}103.314 \\
(15.959)\end{array}$ & $\begin{array}{c}70.751 \\
(39.066)\end{array}$ & $\begin{array}{c}78.963 \\
(36.287)\end{array}$ & \\
\hline $\mathrm{cb}$ & $\begin{array}{c}5.948 \\
(2.592)\end{array}$ & $\begin{array}{c}7.485 \\
(6.419)\end{array}$ & $\begin{array}{c}-6.595 \\
(3.509)\end{array}$ & $\begin{array}{c}-2.851 \\
(3.084)\end{array}$ & $\begin{array}{c}3.964 \\
(3.116)\end{array}$ & $\begin{array}{c}8.091 \\
(3.898)\end{array}$ & $\begin{array}{c}-2.185 \\
(1.413)\end{array}$ & $\begin{array}{c}1.775 \\
(5.720)\end{array}$ & \\
\hline pdi & $\begin{array}{c}84.896 \\
(23.228)\end{array}$ & $\begin{array}{c}80.186 \\
(31.813)\end{array}$ & $\begin{array}{c}76.062 \\
(32.015)\end{array}$ & $\begin{array}{c}78.114 \\
(28.672)\end{array}$ & $\begin{array}{c}88.749 \\
(32.388)\end{array}$ & $\begin{array}{c}92.479 \\
(18.971)\end{array}$ & $\begin{array}{c}84.511 \\
(29.934)\end{array}$ & $\begin{array}{c}84.255 \\
(27.259)\end{array}$ & \\
\hline ur & $\begin{array}{c}5.877 \\
(1.484)\end{array}$ & $\begin{array}{c}3.832 \\
(1.087)\end{array}$ & $\begin{array}{c}8.587 \\
(3.153)\end{array}$ & $\begin{array}{c}16.784 \\
(5.002)\end{array}$ & $\begin{array}{c}6.381 \\
(2.533)\end{array}$ & $\begin{array}{c}2.931 \\
(1.297)\end{array}$ & $\begin{array}{c}7.258 \\
(1.968)\end{array}$ & $\begin{array}{c}7.492 \\
(4.090)\end{array}$ & \\
\hline rir & $\begin{array}{c}3.291 \\
(2.166)\end{array}$ & $\begin{array}{c}2.721 \\
(5.264)\end{array}$ & $\begin{array}{c}3.116 \\
(2.788)\end{array}$ & $\begin{array}{c}3.332 \\
(2.296)\end{array}$ & $\begin{array}{c}3.375 \\
(2.351)\end{array}$ & $\begin{array}{l}1.730 \\
(1.334)\end{array}$ & $\begin{array}{c}2.907 \\
(1.853)\end{array}$ & $\begin{array}{c}3.184 \\
(2.686)\end{array}$ & \\
\hline credit & $\begin{array}{c}98.534 \\
(20.356)\end{array}$ & $\begin{array}{c}79.186 \\
(28.696)\end{array}$ & $\begin{array}{c}99.445 \\
(40.707)\end{array}$ & $\begin{array}{l}106.719 \\
(38.531)\end{array}$ & $\begin{array}{c}75.604 \\
(39.079)\end{array}$ & $\begin{array}{l}150.586 \\
(11.009)\end{array}$ & $\begin{array}{l}128.077 \\
(37.467)\end{array}$ & $\begin{array}{c}92.891 \\
(37.444)\end{array}$ & \\
\hline $\operatorname{tax}$ & $\begin{array}{c}79.626 \\
(14.641)\end{array}$ & $\begin{array}{l}47.766 \\
(7.328)\end{array}$ & $\begin{array}{c}23.082 \\
(9.798)\end{array}$ & $\begin{array}{c}77.500 \\
(11.175)\end{array}$ & $\begin{array}{c}58.272 \\
(24.070)\end{array}$ & $\begin{array}{c}74.065 \\
(16.019)\end{array}$ & $\begin{array}{l}168.759 \\
(46.575)\end{array}$ & $\begin{array}{c}81.295 \\
(58.600)\end{array}$ & \\
\hline rri & $\begin{array}{l}22.465 \\
(8.557)\end{array}$ & $\begin{array}{c}8.211 \\
(5.409)\end{array}$ & $\begin{array}{l}6.921 \\
(2.224)\end{array}$ & $\begin{array}{c}53.545 \\
(33.299)\end{array}$ & $\begin{array}{l}10.097 \\
(4.498)\end{array}$ & $\begin{array}{l}14.312 \\
(5.047)\end{array}$ & $\begin{array}{c}52.220 \\
(21.393)\end{array}$ & $\begin{array}{c}30.712 \\
(37.891)\end{array}$ & \\
\hline
\end{tabular}

Note: Standard deviation for each variable is presented in parentheses.

smallest standard deviation (11.040), which is nearly four times smaller than Austria. The most volatile hpi among all countries is Norway as it reports the highest standard deviation (45.622). Current account balance seems to be flat as the overall mean value is only 1.775 with relatively low standard deviation (5.720). Luxembourg is the only country with the highest average value of current account balance (10.731), while for Portugal we find the lowest value, which is -6.595 . The independent variables, such as pdi, credit, and tax, present similar distributional characteristics with respect to mean; the values are 84.255, 92.891, and 81.295, respectively. Notably, tax rate exhibits dramatic fluctuations compared with $p d i$ and credit. Besides, on average, ur is 7.492. The country with the highest mean value of ur is Spain (16.784), while the same in Switzerland exhibits the smallest magnitude (2.931). Real interest rate ( ir ) across countries presents a uniform pattern; the average across countries is 3.184 and various countries seem to move around the average value with no extreme skewness. The highest mean value of $\mathrm{rir}$ is in Ireland, which is only a magnitude of 2.814 greater than the lowest counterpart in Switzerland. In contrast, rri varies dramatically across countries. Germany is the country which has the highest average rri (122.545), while the 
smallest mean value of $r r i$ is for Luxembourg (a value of only 0.803).

\subsection{Preliminary observations}

To motivate our main empirical analyses, we first discuss important preliminary empirical facts concerning our data. We focus on three aspects, viz., (i) evidence of correlation of house prices at an international level, (ii) an exploration of the spatial distributions of house prices and (iii) a possible non-stationary nature of the data. Each aspect is presented in the form of a stylized observation.

\section{(a) Housing prices at cross-country level depict significant correlation}

To demonstrate that cross-country house prices are interdependent by nature, we compute crosscountry moving pair-wise correlations over the period 1985-2015. Figure 2 presents the trend in these correlations. Likewise, in Figure 3, we have presented pair-wise correlations for selected macroeconomic variables.

Figure 2: The Cross-country Average of Moving Pair-wise Correlation for House Prices

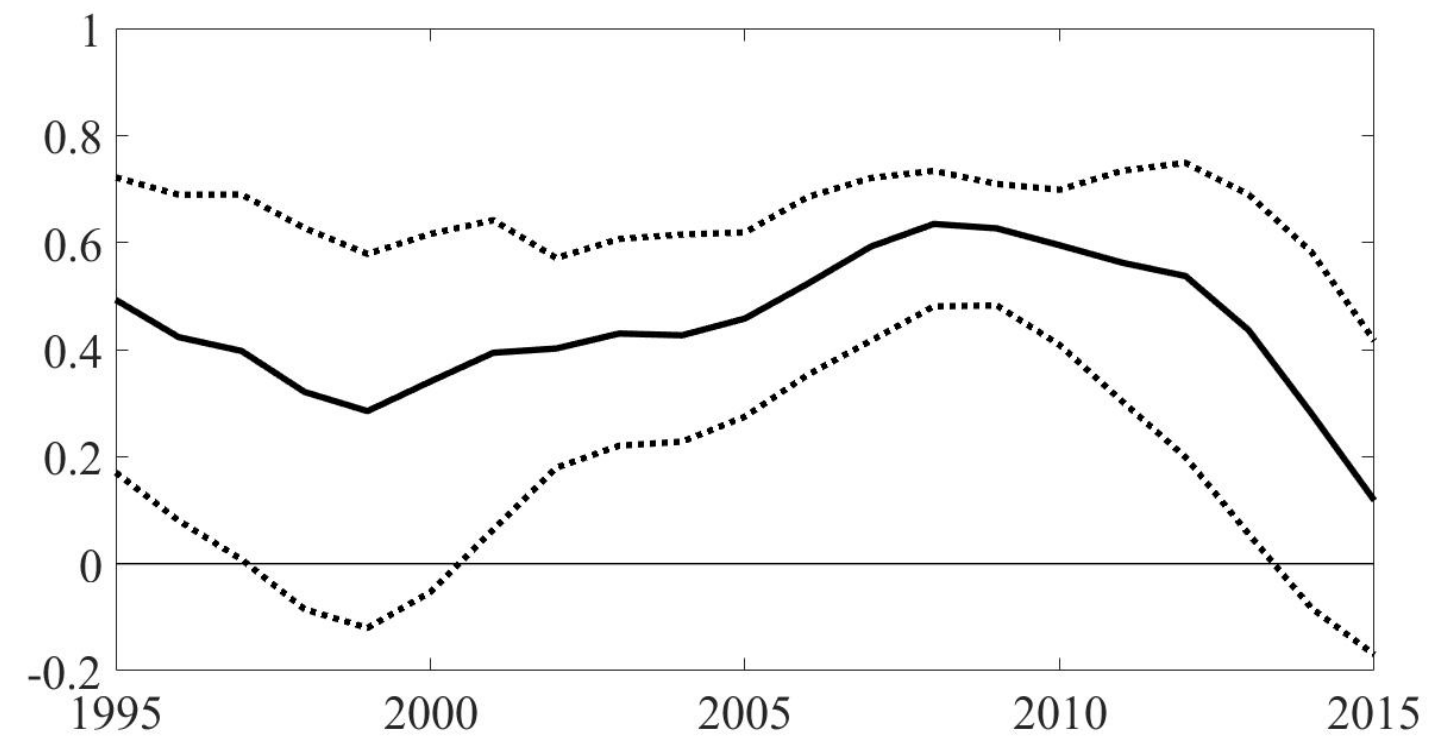

Note: The average cross-country pair-wise correlation of $x$ for country $i$ is measured by: $\rho_{i}=\left(\sum_{j=1}^{N} \operatorname{COR}\left(x_{i}, x_{j}\right)-1\right) /(N-1) ; \operatorname{COR}\left(x_{i}, x_{j}\right)$ is the specific pair-wise correlation of variable $x$ between country $i$ and $j . N$ : number of countries; based on the evidence shown in figure 1 , we choose 10 years as the rolling window period (for this reason, the $\mathrm{X}$-axis begins with the year 1995).

Interesting patterns of correlation of house prices emerge from Figure 2; the correlation varies from 0.3 to 0.6 across countries over most decades, reaching a peak in 2008 possibly due to the subprime crisis, and witnessing a dramatic fall after 2012. Although the correlation tends to have a relatively large error band at the 5\% significant level, it remains significant over three decades. 
This significant correlation provides indirect evidence of house price synchronizations over time. Considering the pattern of correlation for selected macroeconomic variables (in Figure 3), we find that the correlation coefficients of real interest rates, mortgage loan volumes, and residential investment among these countries are largely positive and significant. Following our hypothesis of international synchronization of housing prices, we can premise that the correlation of macroeconomic policy variables at international level can determine the cross-country interdependence of housing prices. This premise needs to be tested rigorously, which we undertake in the next section with a dynamic SDM model estimation.

Figure 3: The Time Average of Cross-country Pairwise Correlation

(a) Real Interest Rate

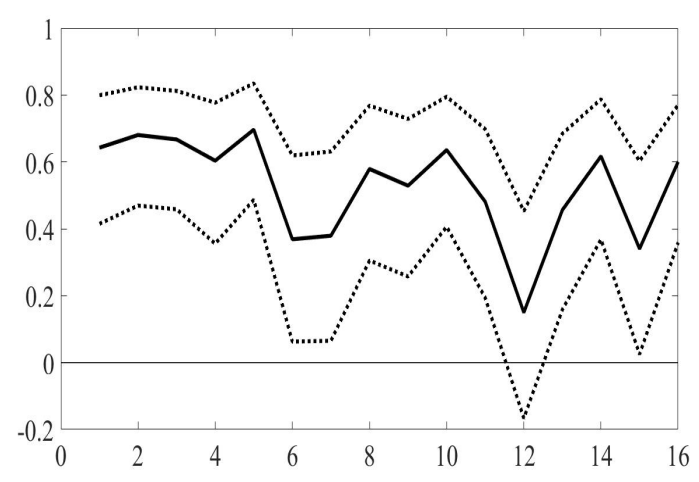

(c) Taxation

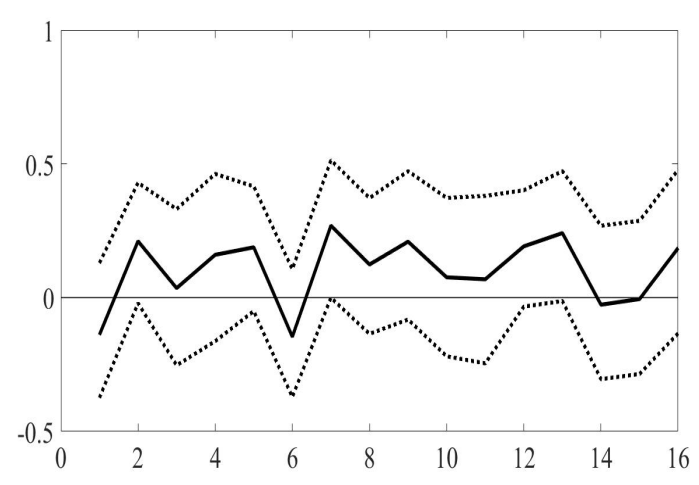

(b) Mortgage loan volumes

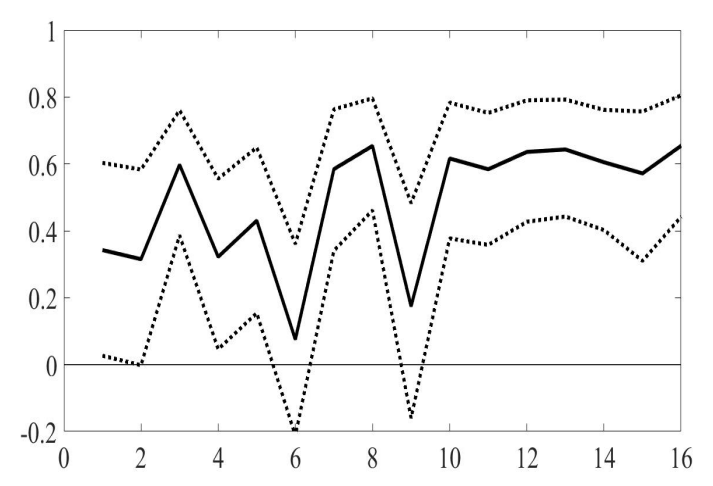

(d) Residential Investment

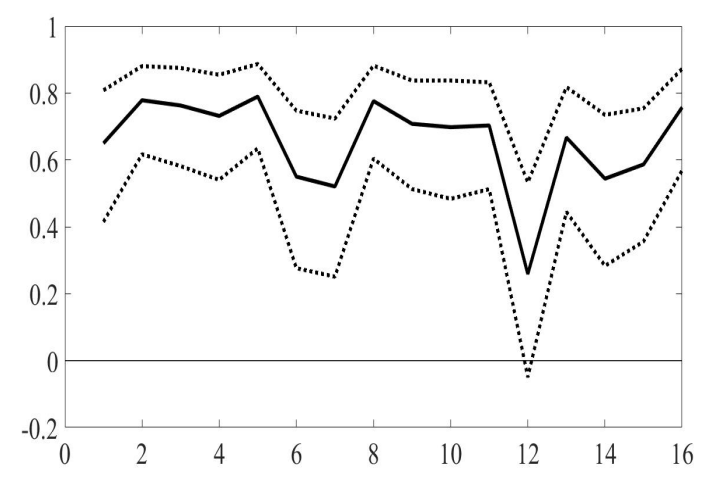

\section{(b) The distributions of house prices across countries depict significant spatial movements}

Due to the spatio-temporal nature of our data and the objective of employing a spatio-temporal method to our theoretical construct, it is necessary to provide some evidence of spatial dependence of house prices over time. To do so, we study the distribution ${ }^{17}$ of house prices across 16 European

\footnotetext{
${ }^{17}$ We present here only mean and standard deviation distributions of house prices to save space. Year-to-year-wise distributions are available from the authors upon request.
} 
countries. For this purpose, we have used geographical coordinates (latitude and longitude) of each country and have identified spatial clusters of low/high housing prices for each year since 1985. The sub-plots in Figure 4 present the spatial correlation of house prices for 16 European countries with respect to their mean (left panel) and standard deviation (right panel) of housing prices over the period 1985-2015.

Figure 4: Spatial Distributions of House Prices: Mean and Standard Deviation
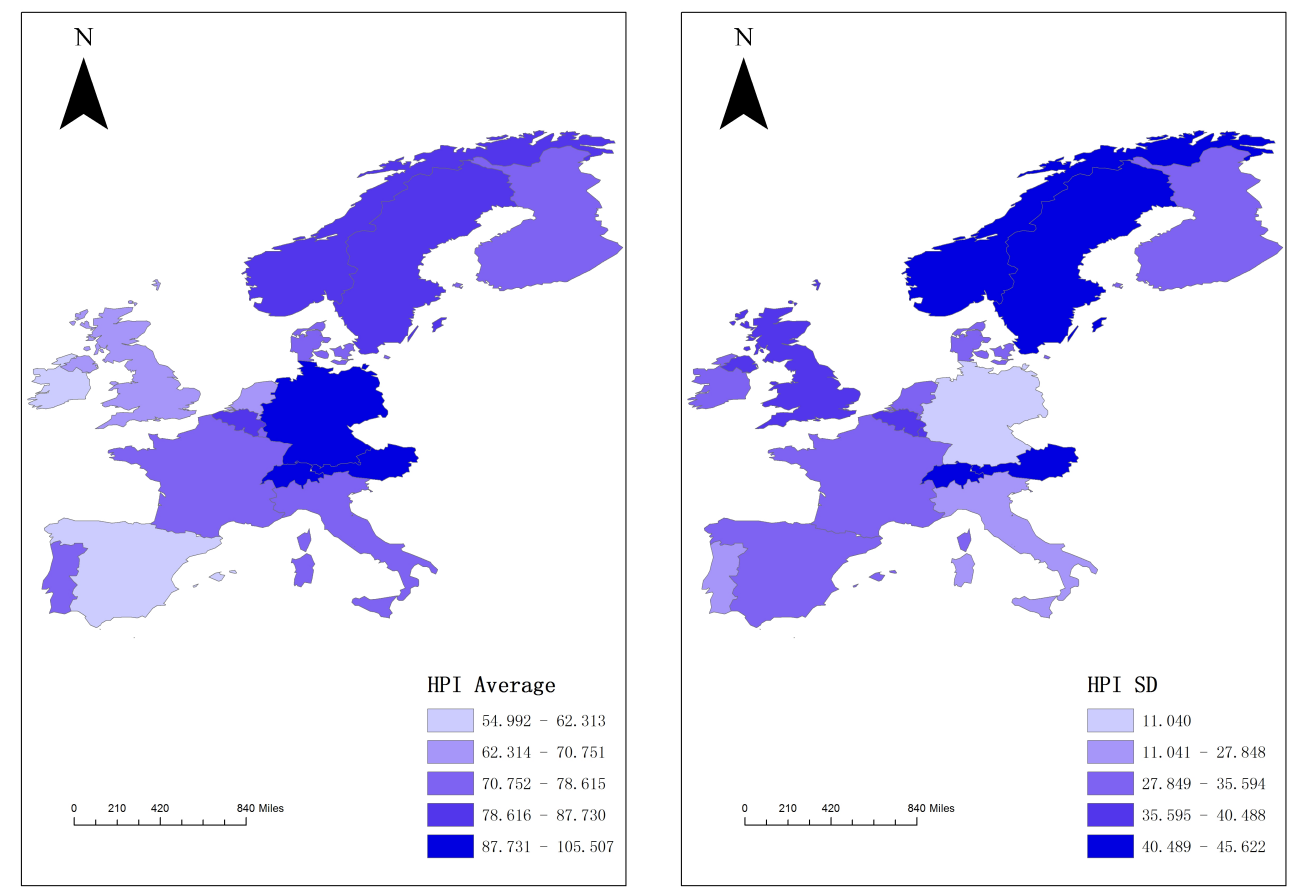

The leading idea in Figure 4 is to identify whether the average and dispersion in house prices and corresponding country dispersions share spatial affinities. Indeed, this is the case for our data. If we study the left panel of Figure 4, we observe that over the 30-year time periods, countries located in Northern and Central Europe (such as Germany, Norway and Sweden) demonstrate relatively higher house prices than countries in Western and Southern Europe (such as Ireland and Spain) do. We note that countries with similar average house prices tend to cluster together indicating that there can be positive spatial autocorrelation of house prices across countries. A similar pattern is observed for the dispersion of house prices (right panel of Figure 4); there are similarities in the standard deviation across clusters of countries. For instance, countries in Northern Europe (viz., Norway, Sweden, and Finland, among others) share similar magnitudes of high dispersion, whereas Central European Countries (viz., France, Germany, and Italy, among others) present a cluster of low dispersion of prices. Taking together the results of both panels in Figure 4 , we observe what we term as 'spatial herding behavior' in the housing market. This graphical evidence of spatial clustering is also supported by Moran's I test.

The results of Moran's I test are presented in Table B1 in Appendix B. Generally speaking, the majority of $Z$ values are found to be positive indicating the presence of positive spatial auto- 
correlation of house prices across 16 European countries over the period 1985-2015. This can be taken as evidence of housing price synchronizations across countries. Interestingly, different from the conclusions in existing research in this context, we find that housing prices exhibit negative spatial autocorrelation between 2000 and 2008 (see the negative $Z$ values). ${ }^{18}$ This phenomenon can be interpreted as "geographic competition" in contrast to "geographic cooperation" (Griffith, 1987). It implies that the increase in house prices in one region can only occur through the decline of housing prices in the adjacent location under the assumption of finite resource availability in these countries. Most importantly, after the subprime crisis in 2008 we observe a significant positive spatial autocorrelation. Moreover, the strength of the spatial autocorrelation also appears to increase over time (see the $Z$ value). These results motivate us to study international housing prices using a spatio-temporal method. In Section 5, we present and analyze results from the estimation of the SDM method in this context.

\section{(c) Cross-country house prices and their determinants possess non-stationary components}

Before estimating the dynamic spatial Durbin model (SDM), it is necessary to investigate whether the variables in our study are stationary. This will minimize the risk of running spurious spatial regression in the data (see, for instance, Baltagi et al. (2007); Mur and Trívez (2003)). We perform three types of panel unit root tests, viz., the $L L C$ test (Levin et al., 2002), the IPS test (Im et al., 2003), and the PESCADF test (Pesaran, 2004). The results are summarized in Table B2 in Appendix B.

We perform an estimation with and without allowing for cross-sectional dependence and the trend term. We find that real interest rate ( rir) is stationary - a result which is consistent across majority of test methods. On the other hand, both mortgage loan volumes (credit) and taxation on dwellings over house prices $(\operatorname{tax})$ are found to be non-stationary (using $L L C, I P S$, and PESCADF tests). The first difference of these variables $(d=1)$ is found to be stationary in each test method. Due to the overlapping results, we prefer to choose the first-difference of the variables in our following empirical estimation.

\section{Main empirical results}

We now present the main empirical results and supplement our findings with a series of robustness exercises. Model performance of the SDM specification forms the final empirical exercise of the paper. To proceed, we first summarize the results of the model selection estimation. This is followed by our analyses of various empirical results related to the SDM estimation.

\footnotetext{
${ }^{18}$ A similar phenomenon of negative spatial autocorrelation of house prices has also been reported in the literature, viz., Kuethe and Pede (2011) and Ma and Liu (2015).
} 


\subsection{Model selection}

A pre-requisite for selecting the final estimation equation for our SDM model is to decide whether a fixed effects specification ${ }^{19}$ is a better model choice than a random effects specification. Following convention, we employ the Hausman specification test. In our case, the estimated Hausman test statistic (following a Chi-square distribution) is 965.20. This is significantly greater than the critical value of 25.00 at the 5\% level of significance, implying that SDM with fixed effects is our chosen specification. ${ }^{20}$ Although from a theoretical perspective (see Section 3 for discussion), SDM is known to perform better than other spatial panel models (such as SAR and SEM), we need to confirm this by using a likelihood ratio (LR) test. Using the LR test we would like to demonstrate that SDM is the most appropriate specification for our data (Elhorst, 2010). On the basis of both equations (11) and (13), ${ }^{21}$ first, we test the null hypothesis $H_{0}: \eta=0$, i.e. whether SDM can be simplified to SAR. The LR statistic is 22.95, which exceeds the critical value of 14.07 at the $5 \%$ significance level. The second null hypothesis concerns $H_{0}: \eta+\rho \zeta=0$, i.e. whether SDM can be simplified to SEM. The estimated LR statistic in this case is 22.43 , which is larger than 14.07 at the 5\% significance level. Due to the rejections of both null hypotheses, we can now regard SDM as the best model to fit our data. Our final LR test concerns whether a static SDM is preferable to the dynamic one. Accordingly, we test $H_{0}: \beta=\gamma=0$ where we obtain the $L R=2 \times(-1142.2321+1284.1955)=283.9268$. Once again, the LR statistic is greater than the critical value of 5.99 at the $5 \%$ significance level, thus strongly rejecting the null hypothesis of a static SDM model in favor of the dynamic SDM model. To summarize the model selection procedure, the various LR tests lead us to select the dynamic spatial Durbin model (SDM) with spatial fixed effects to carry out further estimation.

\subsection{Discussion of results from SDM estimation}

In Tables 4-8, we present the results from OLS and SDM estimation, including the series of robustness exercises. The main estimation results are presented in Table 4, whereas results in Tables 5-8 concern robustness exercises. In all tables, variables in 'first differenced' forms begin with a prefix ' $\mathrm{d}$ '. In Table 4, columns 1 and 3 describe the results estimated by the conventional OLS method without considering spatial spill-over effects, while columns 2 and 4 present results from the dynamic spatial Durbin model (SDM) method. Besides, columns 1 and 2 include all macroeconomic policy factors, while columns 3 and 4 ignore the effect of selected macroeconomic factors

\footnotetext{
${ }^{19}$ We only add spatial fixed effects and remove time fixed effects, otherwise the convergence requirement of ML estimation cannot not be achieved. Furthermore, the role of time fixed effects to account for effects of unobserved spatial autocorrelated variables in the residuals has already been accommodated by the SDM specification via the addition of both spatial endogenous and exogenous dependencies (Fingleton and Le Gallo, 2010).

${ }^{20}$ This result is consistent with the idea of Elhorst (2012) that the fixed effects model is more appropriate than the random effects model in a spatio-temporal setting. Besides, two prerequisites highlighted by Elhorst are applicable in our context. First, we have a sufficiently long time period ( $T$ equals to 30). Second, we apply SDM as the spatial panel specification, which is known to treat potential endogeneity problems such as the omission of relevant variables (Fingleton and Le Gallo, 2010).

${ }^{21}$ All parameters mentioned here are the coefficients of different variables on the right hand side of equation (13).
} 
on house prices. The "Main" section (upper panel of each table) denotes effects of various independent variables on house prices within a country's geographic boundary, whereas the "Wx" section (lower panel in each table) describes spatial spill-over effects (or across-the-border effects) of independent variables on house prices in the home country. ${ }^{22}$

Several key patterns emerge in the "Main" section of Table 4. First, signs of estimated coefficients in all columns are similar and are consistent with the theoretical expectations previously discussed. One exception is that real residential investment ( rri) is observed to impart a positive impact on house prices. This unexpected effect may be because the sign of $r r i$ tends to change over time, implying that it can have a negative impact in the short term and a positive impact in the long term (Arestis and Gonzalez-Martinez, 2016). Another reason concerns the use of gross fixed capital formation at dwellings to represent residential investment. Since this variable includes the construction cost of dwellings, it induces a positive correlation with house prices (Glaeser and Gyourko, 2003).

Second, dynamic parameters in the SDM model impart significant (positive) effects on house prices. For instance, the coefficient of temporal lag of house prices (L.dhpi) is positive and significant in columns 2 (0.592) and 4 (0.652). Interestingly, in the "Wx" section, the coefficient of the temporally spatial lag of house prices $(L . W d h p i)$ is negative, and it appears to offset the positive effect produced by the contemporaneous spatial lag of house prices (Wdhpi). ${ }^{23}$ In addition, the summation of effects of temporally spatial lag (L.Wdhpi) and contemporaneous spatial lag (Wdhpi) of house prices triggers significantly positive effects ( 0.061 and 0.227 in columns 2 and 4, respectively), which confirm theoretical expectation indicating the presence of positive spatial autocorrelation of house prices. This result can be considered as a transmission mechanism through which house cycles across international borders are synchronized.

Third, in the absence of spatial spillover effects, the impact of macroeconomic variables may be over-estimated (in terms of the absolute values). Specifically, the estimates of taxation on dwellings over house prices (tax) and residential investment (rri) (in column 2) are -0.029 and 0.256 , respectively. Considering their absolute values, 0.029 and 0.256 , the estimated coefficients appear over-estimated if we omit spatial spill-over effects from estimation (compared with the non-spatial estimation). Moreover, the impact of unemployment rate in column 2 is -0.931 , while its corresponding counterparts in column 3 and 4 are -1.698 and -1.317 , respectively. In a similar vein, we can conclude again that the estimated coefficients (in absolute terms) are overestimated. ${ }^{24}$ To summarize, we note that the over-estimation bias of the independent variables in the "Main" section can be minimized by including spatial effects in the model specification. In addition, the omission of the macroeconomic instruments can also induce an over-estimation bias

\footnotetext{
${ }^{22}$ The effect of independent variables in the "Main" and "Wx" sections can be regarded as direct and indirect effects. Note that L.dhpi appears in the 'Main' section, whereas both $W d h p i$ and $L . W d h p i$ appear in the "Wx" section.

${ }^{23}$ Based on the non-linear restriction of the dynamic spatial panel model, Tao and Yu (2012) propose a theoretical framework to justify the way the coefficient of $L . W d h p i$ can be negative in the case that coefficients of both temporal lag $(L . d h p i)$ and contemporaneous spatial lag $(W d h p i)$ of house prices are positive.

${ }^{24}$ We remove macroeconomic variables and 'space' in column 3, whereas we remove macroeconomic variables in column 4.
} 
in the dynamics of housing prices. It is worth noting that our results (on the significant effect of macroeconomic policy variables, viz., taxation on dwellings over house prices and real interest rates) are also consistent with the existing studies such as Arestis and Gonzalez-Martinez (2016).

We now turn our attention to the "Wx" section. The coefficient estimates presented here correspond to spatial-spillover effects. In other words, the estimates represent the responses in housing prices to the changes in independent variables among spatially contiguous countries. These effects are also sometimes termed 'indirect effects'. We find that some variables, such as taxation on dwellings and residential investment, impart significant negative and positive spatial spill-over effects on house prices, respectively. Both variables present significant direct effects as well (in the same direction as their corresponding indirect effects). Interestingly, the indirect effects of some independent variables show opposite signs with their corresponding direct effects.

Consider for example, the case of current account balance $(c b)$. We note that instead of the observed negative direct effect as in the "Main" section, $c b$ now presents strong positive spatial spill-over effects (0.589 and 0.641, respectively in columns $2 \& 4)$. Besides, personal disposable income $(p d i)$ is also observed to exert a positive direct effect on house prices, which is theoretically expected. ${ }^{25}$ However, this positive direct effect in the "Main" section can be offset by the large negative indirect effect in the "Wx" section as shown in columns 2 and 4, respectively. The coefficient of the indirect effect of personal disposable income witnessed a 0.26 point increase after omitting macroeconomic interventions (column 4) in comparison with the situation before removing macroeconomic variables from the estimation (column 2). In addition, in terms of model fit, the observed highest $R^{2}$ in column 2 also reflects the fact that both spatial spill-over effects and macroeconomic policy interventions are of paramount importance in interpreting house price fluctuations across international real estate markets. Overall, the significant spillover effect of macroeconomic variables help us understand the fundamental reasons behind international house prices synchronization.

The above results have implications for the 'catching up' problem of house prices across countries. Indeed, due to the co-movement of macroeconomic fundamentals and the evidence of synchronized housing price cycles, we can conclude that cross-country house prices depict spatial clustering. This inference is consistent with previous studies such as Cesa-Bianchi (2013) and Arestis and Gonzalez-Martinez (2016).

\subsection{Robustness}

We perform a number of robustness checks to establish the generality of our results. Four directions are considered: alternative estimation method, introduction of new variables in our estimation, structural break, and extension of the sample span. We study the results from each investigation below.

\footnotetext{
${ }^{25}$ Örsal (2014) also find a positive effect of real GDP per capita on house price fluctuations.
} 
Table 4: Main Results (Non-spatial Model and Dynamic SDM)

\begin{tabular}{|c|c|c|c|c|}
\hline Variables & col.(1) & col.(2) & col.(3) & col.(4) \\
\hline \multicolumn{5}{|l|}{ Main: Within-country effects } \\
\hline $\mathrm{dcb}$ & $\begin{array}{c}-0.117 \\
(0.100)\end{array}$ & $\begin{array}{c}-0.024 \\
(0.079)\end{array}$ & $\begin{array}{r}-0.175 * \\
(0.106)\end{array}$ & $\begin{array}{c}-0.045 \\
(0.080)\end{array}$ \\
\hline dpdi & $\begin{array}{l}0.414 * * * \\
(0.103)\end{array}$ & $\begin{array}{c}0.123 \\
(0.083)\end{array}$ & $\begin{array}{l}0.612 * * * \\
(0.110)\end{array}$ & $\begin{array}{c}0.177 * * \\
(0.086)\end{array}$ \\
\hline dur & $\begin{array}{c}-0.982 * * * \\
(0.204)\end{array}$ & $\begin{array}{c}-0.931 * * * \\
(0.183)\end{array}$ & $\begin{array}{c}-1.698 * * * \\
(0.203)\end{array}$ & $\begin{array}{c}-1.317 * * * \\
(0.175)\end{array}$ \\
\hline drir & $\begin{array}{c}-0.075 \\
(0.083)\end{array}$ & $\begin{array}{c}-0.043 \\
(0.066)\end{array}$ & & \\
\hline dcredit & $\begin{array}{l}0.056 * * * \\
(0.021)\end{array}$ & $\begin{array}{c}0.007 \\
(0.017)\end{array}$ & & \\
\hline dtax & $\begin{array}{c}-0.052 * * * \\
(0.016)\end{array}$ & $\begin{array}{c}-0.029 * * \\
(0.012)\end{array}$ & & \\
\hline drri & $\begin{array}{l}0.456 * * * \\
(0.052)\end{array}$ & $\begin{array}{l}0.256 * * * \\
(0.041)\end{array}$ & & \\
\hline L.dhpi & & $\begin{array}{l}0.592 * * * \\
(0.034)\end{array}$ & & $\begin{array}{l}0.652 * * * \\
(0.035)\end{array}$ \\
\hline C & $\begin{array}{l}1.451 * * * \\
(0.339)\end{array}$ & & $\begin{array}{l}1.434 * * * \\
(0.369)\end{array}$ & \\
\hline \multicolumn{5}{|l|}{ Wx: Spillover effects } \\
\hline $\mathrm{Wdcb}$ & & $\begin{array}{c}0.589 * * \\
(0.250)\end{array}$ & & $\begin{array}{l}0.641 * * * \\
(0.249)\end{array}$ \\
\hline Wdpdi & & $\begin{array}{c}-0.675 * * * \\
(0.218)\end{array}$ & & $\begin{array}{c}-0.415 * * \\
(0.210)\end{array}$ \\
\hline Wdur & & $\begin{array}{c}0.265 \\
(0.380)\end{array}$ & & $\begin{array}{c}0.430 \\
(0.364)\end{array}$ \\
\hline Wdrir & & $\begin{array}{c}-0.131 \\
(0.157)\end{array}$ & & \\
\hline Wdcredit & & $\begin{array}{c}0.035 \\
(0.044)\end{array}$ & & \\
\hline Wdtax & & $\begin{array}{c}-0.064 * * \\
(0.031)\end{array}$ & & \\
\hline Wdrri & & $\begin{array}{l}0.297 * * * \\
(0.114)\end{array}$ & & \\
\hline Wdhpi & & $\begin{array}{l}0.343 * * * \\
(0.076)\end{array}$ & & $\begin{array}{l}0.519 * * * \\
(0.059)\end{array}$ \\
\hline L.Wdhpi & & $\begin{array}{c}-0.282 * * * \\
(0.085)\end{array}$ & & $\begin{array}{c}-0.292 * * * \\
(0.083)\end{array}$ \\
\hline Residual variance $\left(\sigma^{2}\right)$ & & $\begin{array}{l}8.215 * * * \\
(0.524)\end{array}$ & & $\begin{array}{l}9.110 * * * \\
(0.585)\end{array}$ \\
\hline$R^{2}$ & 0.406 & 0.656 & 0.274 & 0.587 \\
\hline Country Fixed Effects & Included & Included & Included & Included \\
\hline Observations & 480 & 464 & 480 & 464 \\
\hline No. of Countries & 16 & 16 & 16 & 16 \\
\hline
\end{tabular}

Note: *: Significance at $10 \%$ level; ${ }^{* *}$ : Significance at $5 \%$ level; ${ }^{* * *}$ : Significance at $1 \%$ level; Standard errors are in parentheses. 


\subsubsection{Alternative estimation strategy: Estimation by Partial Derivative (PD) method}

Following Elhorst (2014) we know that the dynamic SDM can also be estimated by using the partial derivative $(P D)$ method so that both long-run and short-run direct and indirect effects of the independent variables can be discerned. Results obtained by the $P D$ method can be compared directly with the one we already have obtained by the $M L$ method. ${ }^{26}$ Table 5 presents results from the $P D$ estimation of the SDM model. Columns 5 and 7 are for the dynamic SDM estimations that include different types of macroeconomic factors. Conversely, results in columns 6 and 8 concern dynamic SDM estimations after removing macroeconomic policy factors. Moreover, columns 5 and 6 report the short-run direct/indirect effects, and columns 7 and 8 display the corresponding long-run direct/indirect effects. Specifically, both direct effects ("Main" section) and indirect effects ("Wx" section) of independent variables estimated by either $P D$ or $M L$ depict similar patterns in both sign and magnitude. Pronounced in the long-run period, both direct and indirect effects of each independent variable become larger in absolute values compared with that of the short-run period.

\subsubsection{Replacing residential investment by TFP}

As a further sensitivity analysis, we replace real residential investment by total factor productivity (TFP). ${ }^{27}$ Because TFP is often regarded as a better proxy for construction cost, it depicts strong positive correlation with construction cost and can exert positive impact on house prices (Moro and Nuño, 2012). Besides, as mentioned above, residential investment in our paper is represented by gross fixed capital formation at dwellings, which includes the construction cost of residential buildings. The results are presented in Table 6. In terms of the "Main" section, the results broadly mimic our main estimation (Table 4). Our replacement variable for residential investment, the TFP in the first difference, is also found to have a significant and positive impact on house prices. It leaves a similar direct effect in the non-spatial panel model (column 9) and the dynamic SDM model (column 10) (the estimates are 25.680 and 25.150, respectively). The impacts of unemployment rate, real interest rate, and taxation on dwellings over house prices are also consistent with the results from the main regression, depicting a significantly negative effect over the full sample span. In addition, the significant positive autocorrelation of housing prices in both spatial and temporal dimensions also confirms the existence of house price synchronizations. Apart from the positive impact of TFP in the "Main" section, we also find that there is a positive spatial spill-over effect on housing prices (45.970) and this result is consistent with the results in the main estimation (in Table 4).

\footnotetext{
${ }^{26}$ The analytical derivations concerning direct/indirect effects are available from the authors upon request.

${ }^{27}$ Due to data unavailability for TFP, the sample span for this exercise is therefore limited to 10 European countries between 1995 and 2010.
} 


\subsubsection{Sensitivity to structural break}

Are our results sensitive to the structural break in the data? To investigate this, we have performed an estimation for two sub-sample periods, viz., before and after the subprime crisis (we identify this for the year 2008). We perform a Chow test (with known breakpoint) to investigate if the parameters are stable over time. For our sample, the null hypothesis of time stability for a break point in 2008 is rejected, at the 5\% level of significance (the Chi-square statistic is 34.72). Indeed, it is well-known that housing prices witnessed a sharp decline during the subprime crisis (Posedel and Vizek, 2009). Consequently, the patterns of spatial autocorrelation have also experienced enormous variations before and after 2008. This can be observed from the estimates of Moran's I statistics (shown in Table B1 in Appendix B). Following this test, we estimate and present two separate results with respect to pre- and post-subprime crisis periods. The results are summarized in Table 7. Consistent with the results of full sample estimation (Table 4), we find similar signs and magnitudes of coefficients for both sub-periods (see the effects in the "Main" section). In fact, a study of the variables, viz., unemployment rate and residential investment (in the "Main" section) confirms these inferences. However, we find that the absolute values of the direct effect on changes of house price after the subprime crisis (in column 14) are greater than that of the post crisis period (column 12).

In terms of spatial spill-over (indirect) effects, we find distinct differences in estimated coefficients before/after the subprime crisis. The indirect effects of independent variables before the crisis are similar in magnitudes to the estimates in our main regression (Table 4). However, the significance of indirect effects for each independent variable in the aftermath of the crisis period appears to have changed dramatically. For instance, only mortgage loan volumes appears to have a significant indirect effect in the post-crisis period, which is in contrast to the insignificant effects in the pre-crisis period. The implication is that the outbreak of the subprime crisis has significantly affected the direction and magnitude of spatial spill-over effects (probably making them unstable).

\subsubsection{Broadening the sample coverage}

Our final sensitivity analysis concerns sample enlargement, as it is well-known that change in sample size can have a measurable impact on the coefficient estimates. Accordingly, we have expanded our sample by including additional countries (results are presented in Table 8). In particular, we have added four more countries ${ }^{28}$ to the original sample. The total number of countries now stands at $20 .^{29}$ Table 8 summarizes the results from this investigation. Results in columns 15 and 16 concern all macroeconomic variables, while the results in columns 17 and 18 refer to selected macroeconomic variables related to house price fluctuations. Results in columns 16 and 18 present estimations where 'spatial attributes' forms a part of the explanatory power of the model. In terms of the "Main" section, the direct effects of all variables are similar to the ones we obtained in our main estimation (Table 4). Moreover, the magnitudes of direct effects of all independent

\footnotetext{
${ }^{28}$ These are the Czech Republic, Greece, Iceland, and Slovakia.

${ }^{29}$ Due to the lack of data, we have limited the period of investigation to 16 years (2000 to 2016).
} 
variables in absolute terms are greater than their counterparts in the main regression, except for residential investment. This variable depicts a small direct effect than that of the comparable estimates in the main model (0.201 or 0.422 in the model that considers either spatial spill-over effects (see column 16) or a non-spatial model (see column 15)).

Similar to the implications regarding the consideration of space in our main estimation, we also find in Table 8 that in the absence of spatial spillover effects, the impacts of macroeconomic policy variables are overestimated. Due to the change of the spatial weight matrix (recalling that we have 20 countries in the new sample) the spatial spillover effects (in the "Wx" section) appear to be slightly different from the main estimations (Table 4). However, both signs and magnitudes of the indirect effects in Table 8 remain similar to those our main model (Table 4). Furthermore, commensurate with the main estimation results, the finding of positive spatial autocorrelation of house prices in Table 8 also provides indication of house prices synchronization at the international level.

\section{Figure 5: Dynamic SDM Model Post-estimation}

(a) Predicted Fixed Effects

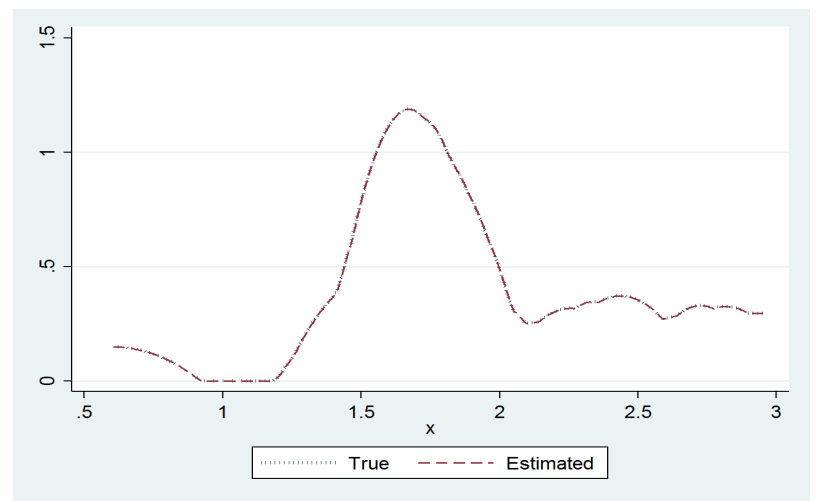

(b) Reduced and Naive Predictors

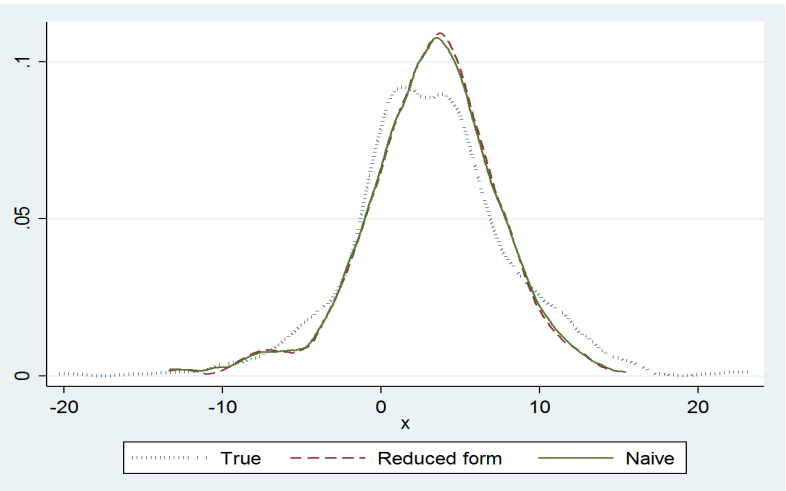

\subsection{Model performance}

How does our SDM method perform vis-a-vis other model specifications? An answer to this question holds the key to ensuring that the results from the SDM estimations are robust and policyinformative. To examine the predictive performance of our dynamic SDM model, we implement two types of post-estimation routines. The latter is based on the comparison of differences in the estimated density of model specifications (Belotti et al., 2017). First, we study the predictive performance of the spatial fixed effects as a deviation between true value (estimated from our dynamic SDM model) and its estimated value. Second, we calculate predicted values of the dependent variable, housing prices (hpi) by using reduced and naive forms, respectively. ${ }^{30}$ The results are presented in Figure 5. We note that the distributions of both true and estimated spatial

\footnotetext{
${ }^{30}$ There are two different statistics to calculate the predicted values based on unique equation forms and information sets. See Belotti et al. (2017) for details.
} 
fixed effects are highly overlapping. In addition, we expect that our main model (the dynamic SDM model) should display better performance in predicting the values of the dependent variable. In Figure 5, while there exists slight deviations between true $h p i$ and two different predicted $h p i$, it might be due to the fact that both predictions are computed without considering the spatial exogenous interactions and the dynamic terms. ${ }^{31}$ Overall, the predictive powers of the SDM associated with both the spatial fixed effects and dependent variable indicate better performance of the model of choice.

\section{Conclusions}

Macroeconomic policy interventions significantly affect house price movements over time; however, adjusting for spatial spillover effects in the model can greatly improve the explanatory power of these variables. To test these predictions in a cross-country setting, we introduce a theoretical model to justify the inclusion of 'space' in the house price-macroeconomy interaction environment.

Our analytical model demonstrates that spatial spillover effects can capture knowledge transmission across countries due to variations in macroeconomic policies. Our empirical estimation in a common market setting provides significant evidence of dynamic spatio-temporal interdependence in house prices. Macroeconomic interventions are found to significantly determine house price equilibrium; however, 'space' is found to play a moderating role towards producing the real effects of these variables. Thus, an important result is derived from our investigation: disregarding spatial spillover effects leads to a consistent over-estimation of the real effects of macroeconomic variables. As a result, in the absence of 'space', an over-emphasis of the role of macroeconomic adjustment policy might lead to a counter-cyclical response of the aggregate economy and underreaction of the housing market over time. In addition, evidence of significant spatial effects in our paper also speaks in favor of the current findings of international housing-price cycle synchronization.

\footnotetext{
${ }^{31}$ Due to the current technical limitation of post-estimation for the SDM model estimated by using $x s m l e$.
} 
Table 5: Robustness Check 1: Dynamic SDM Estimated by Partial Derivative (PD) Method

\begin{tabular}{|c|c|c|c|c|}
\hline Variables & col.(5) & col.(6) & col.(7) & col.(8) \\
\hline & \multicolumn{2}{|c|}{ Short Run Direct } & \multicolumn{2}{|c|}{ Long Run Direct } \\
\hline dcb & $\begin{array}{c}0.011 \\
(0.076)\end{array}$ & $\begin{array}{c}0.017 \\
(0.082)\end{array}$ & $\begin{array}{c}-0.011 \\
(0.186)\end{array}$ & $\begin{array}{c}0.274 \\
(1.007)\end{array}$ \\
\hline dpdi & $\begin{array}{c}0.094 \\
(0.082)\end{array}$ & $\begin{array}{c}0.150 * \\
(0.087)\end{array}$ & $\begin{array}{c}0.269 \\
(0.204)\end{array}$ & $\begin{array}{c}0.340 \\
(0.517)\end{array}$ \\
\hline dur & $\begin{array}{c}-0.935 * * * \\
(0.172)\end{array}$ & $\begin{array}{c}-1.341 * * * \\
(0.163)\end{array}$ & $\begin{array}{c}-2.289 * * * \\
(0.429)\end{array}$ & $\begin{array}{c}-4.166 * * * \\
(1.383)\end{array}$ \\
\hline drir & $\begin{array}{c}-0.043 \\
(0.064)\end{array}$ & & $\begin{array}{c}-0.095 \\
(0.158)\end{array}$ & \\
\hline dcredit & $\begin{array}{c}0.009 \\
(0.017)\end{array}$ & & $\begin{array}{c}0.021 \\
(0.041)\end{array}$ & \\
\hline dtax & $\begin{array}{c}-0.032 * * * \\
(0.011)\end{array}$ & & $\begin{array}{c}-0.075 * * * \\
(0.028)\end{array}$ & \\
\hline drri & $\begin{array}{l}0.274 * * * \\
(0.043)\end{array}$ & & $\begin{array}{l}0.645 * * * \\
(0.104)\end{array}$ & \\
\hline & \multicolumn{2}{|c|}{ Short Run Indirect } & \multicolumn{2}{|c|}{ Long Run Indirect } \\
\hline dcb & $\begin{array}{c}0.877 * * \\
(0.370)\end{array}$ & $\begin{array}{l}1.265 * * * \\
(0.483)\end{array}$ & $\begin{array}{l}1.748 * * \\
(0.789)\end{array}$ & $\begin{array}{c}6.856 \\
(14.550)\end{array}$ \\
\hline dpdi & $\begin{array}{c}-0.957 * * * \\
(0.324)\end{array}$ & $\begin{array}{c}-0.641 \\
(0.419)\end{array}$ & $\begin{array}{c}-1.968 * * * \\
(0.725)\end{array}$ & $\begin{array}{c}-3.072 \\
(6.585)\end{array}$ \\
\hline dur & $\begin{array}{c}-0.072 \\
(0.540)\end{array}$ & $\begin{array}{c}-0.546 \\
(0.666)\end{array}$ & $\begin{array}{c}0.317 \\
(1.156)\end{array}$ & $\begin{array}{l}-6.547 \\
(19.920)\end{array}$ \\
\hline drir & $\begin{array}{c}-0.213 \\
(0.238)\end{array}$ & & $\begin{array}{c}-0.403 \\
(0.495)\end{array}$ & \\
\hline dcredit & $\begin{array}{c}0.056 \\
(0.067)\end{array}$ & & $\begin{array}{c}0.111 \\
(0.143)\end{array}$ & \\
\hline dtax & $\begin{array}{c}-0.114 * * * \\
(0.043)\end{array}$ & & $\begin{array}{c}-0.213 * * \\
(0.099)\end{array}$ & \\
\hline drri & $\begin{array}{l}0.590 * * * \\
(0.158)\end{array}$ & & $\begin{array}{l}1.045 * * * \\
(0.392)\end{array}$ & \\
\hline
\end{tabular}

Note: *: Significance at $10 \%$ level; ${ }^{* *}$ : Significance at $5 \%$ level; ${ }^{* * *}$ : Significance at $1 \%$ level; Standard errors are in parentheses. 
Table 6: Robustness Check 2: The Effect of Replacing Residential Investment by TFP

\begin{tabular}{|c|c|c|}
\hline Variables & col.(9) & col.(10) \\
\hline \multicolumn{3}{|l|}{ Main: Within-country effects } \\
\hline $\mathrm{dcb}$ & $\begin{array}{c}-0.329 \\
(0.290)\end{array}$ & $\begin{array}{r}-0.187 \\
(0.200)\end{array}$ \\
\hline dpdi & $\begin{array}{r}0.405 * \\
(0.220)\end{array}$ & $\begin{array}{c}0.048 \\
(0.170)\end{array}$ \\
\hline dur & $\begin{array}{c}-1.330 * * * \\
(0.350)\end{array}$ & $\begin{array}{c}-0.736 * * * \\
(0.280)\end{array}$ \\
\hline drir & $\begin{array}{c}-0.044 \\
(0.310)\end{array}$ & $\begin{array}{c}-0.818 * * * \\
(0.270)\end{array}$ \\
\hline dcredit & $\begin{array}{c}0.074 \\
(0.051)\end{array}$ & $\begin{array}{c}-0.026 \\
(0.036)\end{array}$ \\
\hline dtax & $\begin{array}{c}-0.123 * * * \\
(0.044)\end{array}$ & $\begin{array}{c}-0.061 * * \\
(0.031)\end{array}$ \\
\hline dtfp & $\begin{array}{l}25.680 * * * \\
(9.670)\end{array}$ & $\begin{array}{l}25.150 * * * \\
(7.270)\end{array}$ \\
\hline L.dhpi & & $\begin{array}{l}0.702 * * * \\
(0.070)\end{array}$ \\
\hline 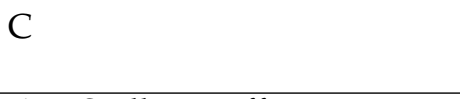 & $\begin{array}{l}2.611 * * * \\
(0.650)\end{array}$ & \\
\hline \multicolumn{3}{|l|}{ Wx: Spillover effects } \\
\hline Wdcb & & $\begin{array}{c}0.401 \\
(0.430)\end{array}$ \\
\hline Wdpdi & & $\begin{array}{c}-0.488 \\
(0.410)\end{array}$ \\
\hline Wdur & & $\begin{array}{c}-0.026 \\
(0.630)\end{array}$ \\
\hline Wdrir & & $\begin{array}{c}0.679 \\
(0.470)\end{array}$ \\
\hline Wdcredit & & $\begin{array}{c}-0.131 \\
(0.110)\end{array}$ \\
\hline Wdtax & & $\begin{array}{c}0.086 \\
(0.091)\end{array}$ \\
\hline Wdtfp & & $\begin{array}{l}45.970 * * * \\
(17.800)\end{array}$ \\
\hline Wdhpi & & $\begin{array}{l}0.372 * * * \\
(0.100)\end{array}$ \\
\hline L.Wdhpi & & $\begin{array}{c}-0.217 \\
(0.150)\end{array}$ \\
\hline Residual variance $\left(\sigma^{2}\right)$ & & $\begin{array}{l}5.826 * * * \\
(0.660)\end{array}$ \\
\hline$R^{2}$ & 0.315 & 0.699 \\
\hline Country Fixed Effects & Included & Included \\
\hline Observations & 150 & 140 \\
\hline Number of Countries & 10 & 10 \\
\hline
\end{tabular}

Note: *: Significance at $10 \%$ level; **: Significance at 5\% level; **: Significance at $1 \%$ level; Standard errors are in parentheses. 
Table 7: Robustness Check 3: The Effect of the Global Financial Crisis

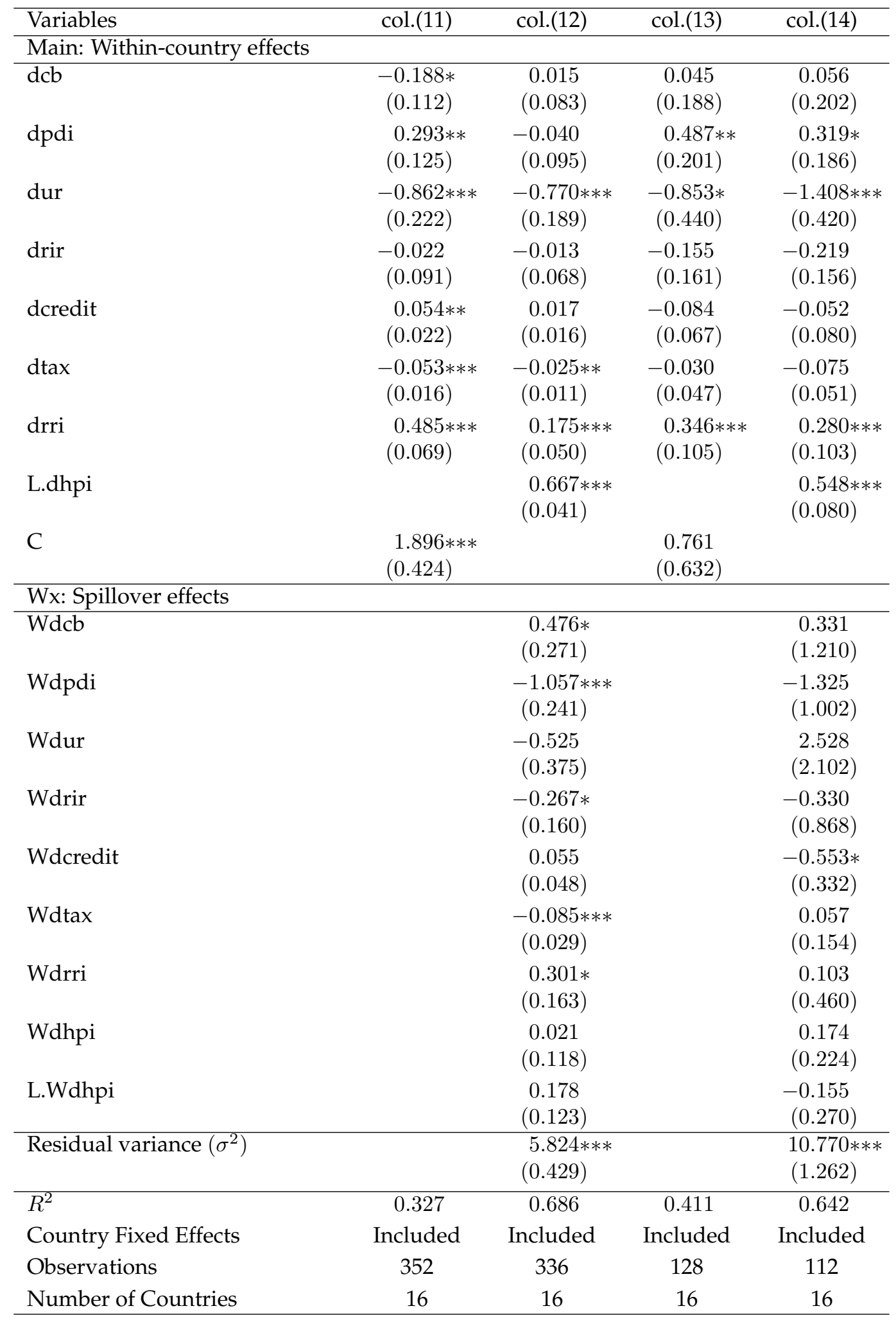

Note: *: Significance at 10\% level; **: Significance at $5 \%$ level; **: Significance at $1 \%$ level; Standard errors are in parentheses. 
Table 8: Robustness Check 4: The Effect of Extension to 20 OECD Countries

\begin{tabular}{|c|c|c|c|c|}
\hline Variables & col.(15) & col.(16) & col.(17) & col.(18) \\
\hline \multicolumn{5}{|c|}{ Main: Within-country effects } \\
\hline $\mathrm{dcb}$ & $\begin{array}{c}-0.352 * * * \\
(0.130)\end{array}$ & $\begin{array}{c}-0.346 * * * \\
(0.114)\end{array}$ & $\begin{array}{c}-0.531 * * * \\
(0.132)\end{array}$ & $\begin{array}{c}-0.411 * * * \\
(0.113)\end{array}$ \\
\hline dpdi & $\begin{array}{l}0.535 * * * \\
(0.108)\end{array}$ & $\begin{array}{l}0.255 * * * \\
(0.098)\end{array}$ & $\begin{array}{l}0.595 * * * \\
(0.115)\end{array}$ & $\begin{array}{l}0.217 * * \\
(0.099)\end{array}$ \\
\hline dur & $\begin{array}{c}-1.405 * * * \\
(0.325)\end{array}$ & $\begin{array}{c}-1.277 * * * \\
(0.302)\end{array}$ & $\begin{array}{c}-2.014 * * * \\
(0.305)\end{array}$ & $\begin{array}{c}-1.671 * * * \\
(0.273)\end{array}$ \\
\hline drir & $\begin{array}{c}-0.010 \\
(0.117)\end{array}$ & $\begin{array}{c}-0.071 \\
(0.106)\end{array}$ & & \\
\hline dcredit & $\begin{array}{l}0.074 * * * \\
(0.026)\end{array}$ & $\begin{array}{c}0.011 \\
(0.027)\end{array}$ & & \\
\hline dtax & $\begin{array}{c}-0.062 * * \\
(0.028)\end{array}$ & $\begin{array}{c}-0.046 * \\
(0.026)\end{array}$ & & \\
\hline drri & $\begin{array}{l}0.422 * * * \\
(0.073)\end{array}$ & $\begin{array}{l}0.201 * * * \\
(0.066)\end{array}$ & & \\
\hline L.dhpi & & $\begin{array}{l}0.500 * * * \\
(0.046)\end{array}$ & & $\begin{array}{l}0.563 * * * \\
(0.044)\end{array}$ \\
\hline C & $\begin{array}{l}2.010 * * * \\
(0.448)\end{array}$ & & $\begin{array}{l}2.324 * * * \\
(0.474)\end{array}$ & \\
\hline \multicolumn{5}{|l|}{ Wx: Spillover effects } \\
\hline $\mathrm{Wdcb}$ & & $\begin{array}{c}0.663 * \\
(0.339)\end{array}$ & & $\begin{array}{c}0.570 * \\
(0.331)\end{array}$ \\
\hline Wdpdi & & $\begin{array}{c}0.327 \\
(0.276)\end{array}$ & & $\begin{array}{c}0.312 \\
(0.269)\end{array}$ \\
\hline Wdur & & $\begin{array}{c}0.766 \\
(0.662)\end{array}$ & & $\begin{array}{c}0.972 * \\
(0.519)\end{array}$ \\
\hline Wdrir & & $\begin{array}{c}0.193 \\
(0.314)\end{array}$ & & \\
\hline Wdcredit & & $\begin{array}{c}0.038 \\
(0.079)\end{array}$ & & \\
\hline Wdtax & & $\begin{array}{c}-0.030 \\
(0.056)\end{array}$ & & \\
\hline Wdrri & & $\begin{array}{l}0.455 * * * \\
(0.169)\end{array}$ & & \\
\hline Wdhpi & & $\begin{array}{r}0.172 * \\
(0.100)\end{array}$ & & $\begin{array}{l}0.386 * * * \\
(0.082)\end{array}$ \\
\hline L.Wdhpi & & $\begin{array}{c}-0.340 * * * \\
(0.095)\end{array}$ & & $\begin{array}{c}-0.354 * * * \\
(0.082)\end{array}$ \\
\hline Residual variance $\left(\sigma^{2}\right)$ & & $\begin{array}{l}15.080 * * * \\
(1.191)\end{array}$ & & $\begin{array}{l}\text { 16.460*** } \\
(1.306)\end{array}$ \\
\hline$R^{2}$ & 0.496 & 0.675 & 0.399 & 0.622 \\
\hline Country Fixed Effects & Included & Included & Included & Included \\
\hline Observations & 300 & 280 & 300 & 280 \\
\hline Number of Countries & 20 & 20 & 20 & 20 \\
\hline
\end{tabular}

Note: *: Significance at $10 \%$ level; ${ }^{* *}$ : Significance at $5 \%$ level; ${ }^{* * *}$ : Significance at $1 \%$ level; Standard errors are in parentheses. 


\section{References}

Anselin, L. (1988), Spatial Econometrics: Methods and Models, Vol. 4, Springer Science \& Business Media.

Anselin, L. and Hudak, S. (1992), 'Spatial econometrics in practice: A review of software options', Regional Science and Urban Economics 22(3), 509-536.

Anselin, L., Le Gallo, J. and Jayet, H. (2008), Spatial panel econometrics, in 'The econometrics of panel data', Springer, pp. 625-660.

Arestis, P. and Gonzalez-Martinez, A. R. (2016), 'House prices and current account imbalances in OECD countries', International Journal of Finance E Economics 21(1), 58-74.

Bagliano, F. C. and Morana, C. (2012), 'The great recession: US dynamics and spillovers to the world economy', Journal of Banking $\mathcal{E}$ Finance 36(1), 1-13.

Baltagi, B. H., Bresson, G. and Pirotte, A. (2007), 'Panel unit root tests and spatial dependence', Journal of Applied Econometrics 22(2), 339-360.

Bao, Y. and Ullah, A. (2007), 'The second-order bias and mean squared error of estimators in timeseries models', Journal of Econometrics 140(2), 650-669.

Basu, S. and Thibodeau, T. G. (1998), 'Analysis of spatial autocorrelation in house prices', The Journal of Real Estate Finance and Economics 17(1), 61-85.

Beenstock, M. and Felsenstein, D. (2007), 'Spatial vector autoregressions', Spatial Economic Analysis 2(2), 167-196.

Belotti, F., Hughes, G. and Mortari, A. P. (2017), 'Spatial panel-data models using Stata', Stata Journal 17(1), 139-180.

Beltratti, A. and Morana, C. (2010), 'International house prices and macroeconomic fluctuations', Journal of Banking $\mathcal{E}$ Finance 34(3), 533-545.

Blanchard, O. J., Katz, L. F., Hall, R. E. and Eichengreen, B. (1992), 'Regional evolutions', Brookings Papers on Economic Activity 1992(1), 1-75.

Campos, N. F., Coricelli, F. and Moretti, L. (2014), Economic Growth and Political Integration: Estimating the Benefits from Membership in the European Union Using the Synthetic Counterfactuals Method , Technical report, CEPR Discussion paper No. 9968.

Can, A. (1992), 'Specification and estimation of hedonic housing price models', Regional Science and Urban Economics 22(3), 453-474.

Cesa-Bianchi, A. (2013), 'Housing cycles and macroeconomic fluctuations: A global perspective', Journal of International Money and Finance 37, 215-238. 
De Groot, A. J. and Elhorst, J. (2010), 'Labour market effects of flexicurity from a regional perspective', Tijdschrift voor Economische en Sociale Geografie 101(4), 392-408.

Debarsy, N., Ertur, C. and LeSage, J. P. (2012), 'Interpreting dynamic space-time panel data models', Statistical Methodology 9(1), 158-171.

Égert, B. and Mihaljek, D. (2007), 'Determinants of house prices in Central and Eastern Europe', Comparative Economic Studies 49(3), 367-388.

Elhorst, J. P. (2003), 'Specification and estimation of spatial panel data models', International Regional Science Review 26(3), 244-268.

Elhorst, J. P. (2010), 'Applied spatial econometrics: Raising the bar', Spatial Economic Analysis 5(1), 9-28.

Elhorst, J. P. (2012), 'Dynamic spatial panels: Models, methods, and inferences', Journal of Geographical Systems 14(1), 5-28.

Elhorst, J. P. (2014), Spatial panel models, in 'Handbook of Regional Science', Springer, pp. 16371652.

Elhorst, J. P. and Fréret, S. (2009), 'Evidence of political yardstick competition in France using a two-regime spatial Durbin model with fixed effects', Journal of Regional Science 49(5), 931-951.

Favara, G. and Imbs, J. (2015), 'Credit supply and the price of housing', The American Economic Review 105(3), 958-992.

Fereidouni, H. G., Al-Mulali, U., Lee, J. Y. and Mohammed, A. H. (2016), ‘Dynamic relationship between house prices in Malaysia's major economic regions and Singapore house prices', Regional Studies 50(4), 657-670.

Fingleton, B. and Le Gallo, J. (2010), Endogeneity in a spatial context: Properties of estimators, in 'Progress in Spatial Analysis', Springer, pp. 59-73.

Glaeser, E. L. and Gyourko, J. (2003), 'The impact of building restrictions on housing affordability', Economic Policy Review 9(2), 21-39.

Griffith, D. A. (1987), Spatial Autocorrelation: A Primer, Washington DC: The Association of American Geographers.

Hendershott, P. H. (1995), 'Real effective rent determination: Evidence from the Sydney office market', Journal of Property Research 12(2), 127-135.

Hilbers, M. P. L. C., Banerji, A., Shi, H. and Hoffmaister, M. A. W. (2008), House Price Developments in Europe: A Comparison, Technical report, IMF Working Paper 211, International Monetary Fund. 
Holly, S., Pesaran, M. H. and Yamagata, T. (2011), 'The spatial and temporal diffusion of house prices in the UK', Journal of Urban Economics 69(1), 2-23.

Im, K. S., Pesaran, M. H. and Shin, Y. (2003), 'Testing for unit roots in heterogeneous panels', Journal of Econometrics 115(1), 53-74.

Kelejian, H. H. and Prucha, I. R. (1998), 'A generalized spatial two-stage least squares procedure for estimating a spatial autoregressive model with autoregressive disturbances', The Journal of Real Estate Finance and Economics 17(1), 99-121.

Koroglu, M. and Sun, Y. (2016), 'Functional-coefficient spatial Durbin models with nonparametric spatial weights: An application to economic growth', Econometrics 4(1), 6.

Kuethe, T. H. and Pede, V. O. (2011), 'Regional housing price cycles: A spatio-temporal analysis using US state-level data', Regional Studies 45(5), 563-574.

Lee, L.-F. (2004), 'Asymptotic distributions of quasi-maximum likelihood estimators for spatial autoregressive models', Econometrica 72(6), 1899-1925.

Lee, L.-f. and Yu, J. (2016), 'Identification of spatial Durbin panel models', Journal of Applied Econometrics 31(1), 133-162.

LeSage, J. and Pace, R. K. (2009), Introduction to Spatial Econometrics, New York: CRC Press.

Levin, A., Lin, C.-F. and Chu, C.-S. J. (2002), 'Unit root tests in panel data: Asymptotic and finitesample properties', Journal of Econometrics 108(1), 1-24.

Lizieri, C. and Satchell, S. (1997), 'Property company performance and real interest rates: A regime-switching approach', Journal of Property Research 14(2), 85-97.

Ma, L. and Liu, C. (2015), 'Is there long-run equilibrium in the house prices of Australian capital cities?', International Real Estate Review 18(4), 503-521.

Manski, C. F. (1993), 'Identification of endogenous social effects: The reflection problem', The Review of Economic Studies 60(3), 531-542.

Mian, A. and Sufi, A. (2009), 'The consequences of mortgage credit expansion: Evidence from the US mortgage default crisis', The Quarterly Journal of Economics 124(4), 1449-1496.

Moro, A. and Nuño, G. (2012), 'Does total-factor productivity drive housing prices? A growthaccounting exercise for four countries', Economics Letters 115(2), 221-224.

Mur, J. and Trívez, F. J. (2003), 'Unit roots and deterministic trends in spatial econometric models', International Regional Science Review 26(3), 289-312.

Ord, K. (1975), 'Estimation methods for models of spatial interaction', Journal of the American Statistical Association 70(349), 120-126. 
Örsal, D. D. K. (2014), 'Do the global stochastic trends drive the real house prices in OECD countries?', Economics Letters 123(1), 9-13.

Pesaran, M. H. (2004), General Diagnostic Tests for Cross Section Dependence in Panels, Technical report, CESifo Working Paper 1229; IZA Discussion Paper 1240.

Pisati, M. (2001), 'sg162: Tools for spatial data analysis', Stata Technical Bulletin 60, 21-37.

Posedel, P. and Vizek, M. (2009), 'House price determinants in transition and EU-15 countries', Post-communist Economies 21(3), 327-343.

Poterba, J. M. (1992), 'Taxation and housing: Old questions, new answers', The American Economic Review 82(2), 237-242.

Rosen, S. (1974), 'Hedonic prices and implicit markets: Product differentiation in pure competition', Journal of Political Economy 82(1), 34-55.

Stevenson, S. (2004), 'House price diffusion and inter-regional and cross-border house price dynamics', Journal of Property Research 21(4), 301-320.

Tao, J. and Yu, J. (2012), 'The spatial time lag in panel data models', Economics Letters 117(3), 544547.

Terrones, M. and Otrok, C. (2004), 'The global house price boom', IMF World Economic Outlook (September), 71-89.

Vansteenkiste, I. and Hiebert, P. (2011), 'Do house price developments spillover across euro area countries? Evidence from a global VAR', Journal of Housing Economics 20(4), 299-314.

Wozniak, A. and Murray, T. J. (2012), 'Timing is everything: Short-run population impacts of immigration in US cities', Journal of Urban Economics 72(1), 60-78.

Yu, J., De Jong, R. and Lee, L.-f. (2008), ‘Quasi-maximum likelihood estimators for spatial dynamic panel data with fixed effects when both $n$ and T are large', Journal of Econometrics 146(1), 118-134. 


\section{Appendix A: Representation in matrix form}

We know from equation (5) that our aggregate productivity, $A_{i}(t)$, is given by

$$
A_{i}(t)=\Gamma(t)\left(m h_{i}(t)\right)^{\delta} \prod_{j \neq i}^{N} A_{j}(t)^{\beta D_{i j}}
$$

By re-expressing this equation in logarithmic form, we get

$$
\ln A_{i}(t)=\ln \Gamma(t)+\delta \ln \left(m h_{i}(t)\right)+\ln \left(\prod_{j \neq i}^{N} A_{j}(t)^{\beta D_{i j}}\right)
$$

We re-write the third term on the right hand side of the above formula, then

$$
\ln A_{i}(t)=\ln \Gamma(t)+\delta \ln \left(m h_{i}(t)\right)+\beta \sum_{j \neq i}^{N}\left(D_{i j} \ln A_{j}(t)\right)
$$

To simplify notation, we omit $t$ from the above and expand the equation in matrix form

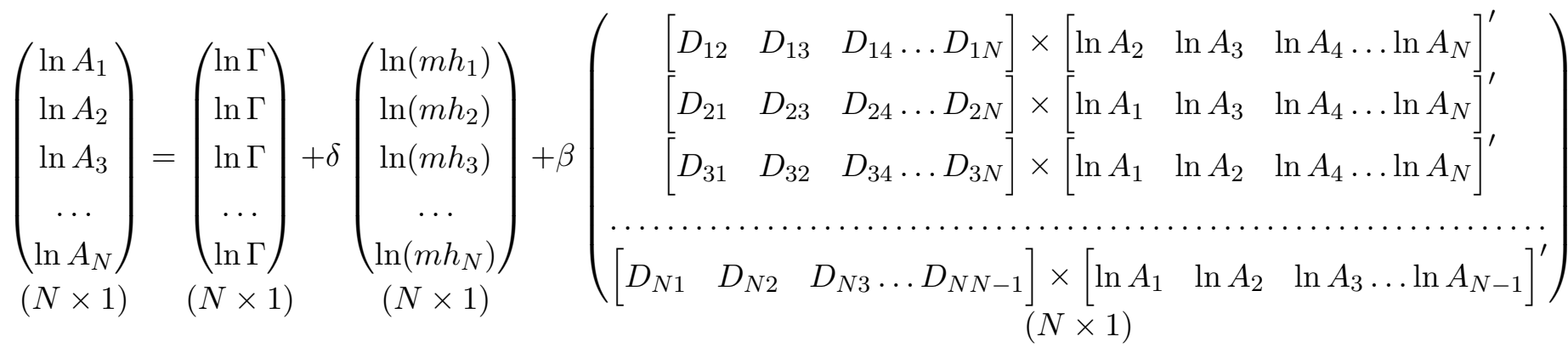

From the above matrix equation, we further expand the third term on the right hand side

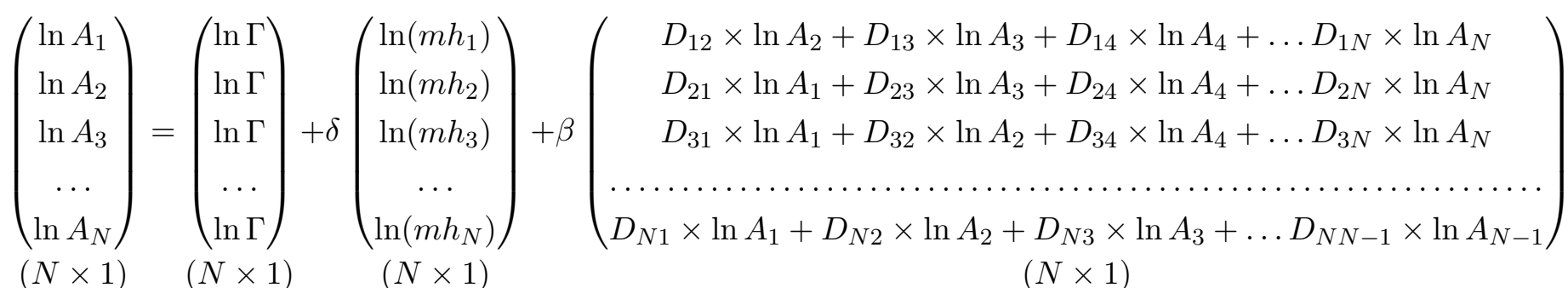

In compact form, the above representation can be written as:

$$
A=\Gamma+\delta m h+\beta D A
$$

Here, $A$ is the $(N \times 1)$ vector of $\ln A_{i} . \Gamma$ is the $(N \times 1)$ constant vector. $m h$ is the $(N \times 1)$ vector of 
$\ln \left(m h_{i}\right) . D$ is the $(N \times N)$ Markov-matrix of $D_{i j}$.

\section{Appendix B}

Moran's I is a popular measure of spatial autocorrelation and is given by:

$$
\text { Moran's } I=\frac{\left[\sum_{i=1}^{N} \sum_{j=1}^{N} W_{i j}\left(Y_{i}-\bar{Y}\right)\left(Y_{j}-\bar{Y}\right)\right] N}{S^{2} \sum_{i=1}^{N} \sum_{j=1}^{N} W_{i j}}
$$

Where $S^{2}=\frac{1}{N} \sum_{i=1}^{N}\left(Y_{i}-\bar{Y}\right)^{2} ; \bar{Y}=\frac{1}{N} \sum_{I=1}^{N} Y_{i}$. In this case, $Y_{i}$ is the house prices in country $i$; $N$ represents 16 target OECD countries. $W_{i j}$ indicates the elements of row-standardized inversedistance spatial weight matrix $W$ corresponding to the country pair $(i, j)$. The expected value of $I, E(I)$, is calculated by $E(I)=\frac{-1}{N-1}$ based on the null hypothesis of no spatial autocorrelation. If $I>E(I)$, the overall distribution of $Y$ can be characterized by positive spatial autocorrelation, indicating that spatially adjacent countries tend to have similar house prices. If $I<E(I)$, it implies negative spatial autocorrelation and presents large dispersion of house prices between spatially neighbouring countries (Pisati, 2001). Moreover, the power of spatial autocorrelation depends on the value of $Z$, which can be calculated as $Z=\frac{I-E(I)}{S D(I)} . S D(I)$ denotes the standard deviation of $I$. The larger is the absolute value of $Z$, the stronger is the pof spatial autocorrelation.

Table B1: Moran's I Statistics for House Prices (1985-2015)

\begin{tabular}{cccccc}
\hline Variables & $Z$ & p-value* & Variables & $Z$ & p-value* $^{*}$ \\
\hline 1985 & 1.215 & 0.112 & 2000 & -0.296 & 0.383 \\
1986 & 1.444 & $0.074 *$ & 2001 & -0.727 & 0.234 \\
1987 & 1.144 & 0.126 & 2002 & -0.942 & 0.173 \\
1988 & 0.906 & 0.182 & 2003 & -1.511 & $0.065 *$ \\
1989 & 0.904 & 0.183 & 2004 & -1.856 & $0.032 * *$ \\
1990 & 1.095 & 0.137 & 2006 & -0.991 & 0.161 \\
1991 & 1.105 & 0.135 & 2007 & -0.100 & 0.460 \\
1992 & 0.968 & 0.167 & 2008 & -0.229 & 0.409 \\
1993 & 0.812 & 0.208 & 2009 & 1.161 & 0.123 \\
1994 & 0.751 & 0.226 & 2010 & 1.990 & $0.023 * *$ \\
1995 & 0.732 & 0.232 & 2011 & 2.117 & $0.017 * *$ \\
1996 & 0.753 & 0.226 & 2012 & 2.036 & $0.021 * *$ \\
1997 & 0.780 & 0.218 & 2013 & 2.119 & $0.017 * *$ \\
1998 & 0.619 & 0.268 & 2014 & 2.074 & $0.019 * *$ \\
1999 & 0.167 & 0.434 & 2015 & 2.132 & $0.017 * *$ \\
\hline
\end{tabular}

Note: (i) *: Significance at $10 \%$ level; ${ }^{* *}$ : Significance at $5 \%$ level; $* * *$ Significance at $1 \%$ level; (ii) $z$ stands for the power of spatial autocorrelation; (iii) 2005 is the reference year. 


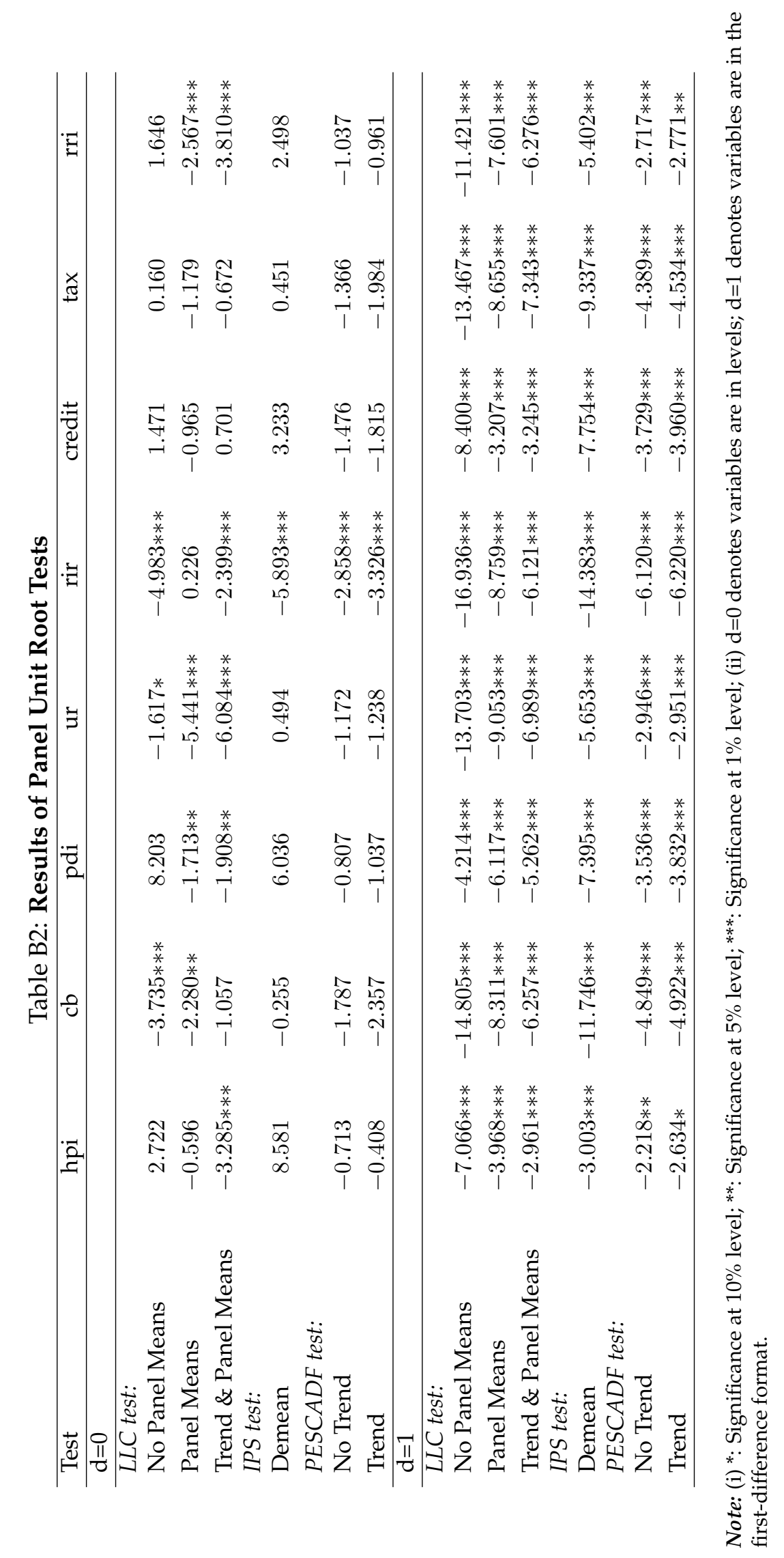

